García González, P., Martínez G.A., Alvarez, M.F., Del Río, J.L., Taverna B.D, (2021). Evaluación de los procesos antrópicos y naturales que inducen la removilización de un campo de dunas sobre la ruta provincial 11, provincia de Buenos Aires, Argentina. GeoFocus (Artículos), Revista Internacional de Ciencia y Tecnología de la Información Geográfica, 27, 135-160. http://dx.doi.org/10.21138/GF.685

\title{
EVALUACIÓN DE LOS PROCESOS ANTRÓPICOS Y NATURALES QUE INDUCEN LA REMOVILIZACIÓN DE UN CAMPO DE DUNAS SOBRE LA RUTA PROVINCIAL 11, PROVINCIA DE BUENOS AIRES, ARGENTINA
}

\author{
1aPABLO GARCÍA GONZÁLEZ, ${ }^{1,2, \mathrm{~b}}$ GUSTAVO ADOLFO MARTÍNEZ, , 1,2,c MARÍA \\ FERNANDA ALVAREZ, ${ }^{1 \mathrm{~d} J U L I O}$ LUIS DEL RÍO, ${ }^{1 \mathrm{l}}$ BERNARDO DANIEL TAVERNA \\ ${ }^{1}$ Instituto de Geología de Costas y del Cuaternario (IGCyC). Facultad de Ciencias Exactas y \\ Naturales, UNMdP-CIC. \\ Deán Funes 3350 - nivel 1, 7600 Mar del Plata, República Argentina Argentina \\ ${ }^{2}$ Instituto de Investigaciones Marinas y Costeras (IIMyC-UNMdP) \\ B7602GSD, Rodríguez Peña 4002-4100, B7602GSD Mar del Plata, Provincia de Buenos Aires, \\ Argentina \\ apablogrgn@gmail.com, ${ }^{\text {b gustavo.gmarti@gmail.com, }}$ ㄹfer_alvarez@yahoo.com.ar, \\ djulioluisdelrio@gmail.com, ${ }^{\mathrm{e}}$ bernardo_san@yahoo.com.ar
}

\section{RESUMEN}

En la costa atlántica de la provincia de Buenos Aires (Argentina), el desarrollo de ciudades, balnearios y de infraestructuras orientadas a la actividad turística presenta diferentes problemáticas ambientales que afectan la dinámica natural de la zona litoral En este trabajo, se evaluaron los procesos antrópicos y naturales que originaron la removilización e intrusión de un campo de dunas sobre la Ruta Provincial 11 que conecta las ciudades de Mar del Plata y Miramar. Se realizaron análisis históricos de la degradación de dunas costeras generadas por tránsito de motos y vehículos doble tracción, con imágenes satelitales y programas de SIG para evaluar cuantitativamente este proceso en el tiempo. Complementariamente se realizaron estudios geomorfológicos, censos de vegetación y análisis granulométricos de los sedimentos removilizados. Se encontró que los principales factores de modificación en el paisaje tienen origen antrópico reciente, siendo necesaria una nueva intervención humana para revertir y mitigar los efectos mal uso del cuerpo medanoso sobre la ruta. Se propone al municipio un plan de gestión que incluye la fijación con vegetación del frente del médano, así como proteger y controlar los usos del área que abarca el sistema medanoso.

Palabras clave: Impacto antrópico; dunas costeras; manejo costero; geomática. 
García González, P., Martínez G.A., Alvarez, M.F., Del Río, J.L., Taverna B.D, (2021). Evaluación de los procesos antrópicos y naturales que inducen la removilización de un campo de dunas sobre la ruta provincial 11, provincia de Buenos Aires, Argentina. GeoFocus (Artículos), Revista Internacional de Ciencia y Tecnología de la Información Geográfica, 27, 135-160. http://dx.doi.org/10.21138/GF.685

\title{
ASSESSMENT OF THE ANTHROPIC AND NATURAL PROCESSES THAT INDUCE THE REMOVAL OF A DUNE FIELD ON PROVINCIAL ROUTE 11, PROVINCE OF BUENOS AIRES, ARGENTINA
}

\begin{abstract}
On the Atlantic coast of the Buenos Aires province (Argentina), the development of coastal cities and infrastructures oriented to tourist activity presents different environmental problems that affects its natural dynamics. In this study, the anthropic and natural processes that originated the remobilization and intrusion of a dune field on Provincial Route 11 connecting the cities of Mar del Plata and Miramar were evaluated. Historical analysis of the degradation of coastal dunes were carried out with satellite images and GIS programs to quantitatively evaluate this process over time. In addition, geomorphological studies, plant censuses and grain size analysis of the remobilized sediments were carried out. It was found that the main factors of modification in the landscape have anthropogenic origin, requiring human intervention to mitigate the effects of the impact of the dune body on the route. A management plan that includes the fixation with vegetation of the front of the dune, as well as protecting and controlling the uses of the area covered by the dune system is proposed.
\end{abstract}

Keywords: Anthropic impact; coastal dunes; coastal management; geomatics.

\section{Introducción}

La compleja interacción entre la atmósfera, el océano y la tierra firme que se desarrolla en la zona costera hace que este ambiente sea caracterizado desde el punto de vista geomorfológico, como una zona muy dinámica y frágil (Arnot 2010). Las zonas costeras constituyen un ambiente muy preciado para el hombre, asentamiento urbano que representan y por la explotación de los recursos que estas brindan. Debido a esta situación se encuentran sometidas a un elevado grado de presión por los usos complejos e intensivos que las distintas sociedades hacen de este ambiente (Brown y McLachlan 2002,_Azuz 2004, Vega de Seoane et al. 2007, Arnot 2010, del Río et al. 2017). Entre estos usos se destaca el incremento, en el último medio siglo, del turismo y la recreación que ha pasado a ser una de las grandes industrias a nivel mundial (Kidd 2001, Dadon et al. 2002).

De manera habitual, el uso de los recursos naturales que brinda el ambiente costero se hace sin tener en cuenta la fragilidad y dinámica que caracterizan este paisaje, por lo que la intervención antrópica repercute en su evolución natural generándose neo ecosistemas (sensu Morello 2000) y paisajes artificiales que pueden desencadenar problemáticas ambientales al interferir con los intereses antrópicos (Nordstrom 2008, Lithgow et al. 2013). La actividad antrópica modifica el ambiente costero a través de distintas intervenciones, construcciones, extracción de recursos, tránsito, recreación, redistribución de sedimentos, plantaciones de vegetación (Nordstrom \& Arens 1998, Marcomini \& López 2006, Nordstrom 2008, Lithgow et al. 2013, del Río et al. 2017). Dentro del ambiente costero los campos de dunas son extremadamente frágiles y vulnerables a la acción humana. A nivel mundial, la elevada presión y frecuentación humana unidas a determinados impactos naturales procedentes del oleaje, erosión o deposición de arenas, provocan que estos ecosistemas estén expuestos a un conjunto 
García González, P., Martínez G.A., Alvarez, M.F., Del Río, J.L., Taverna B.D, (2021). Evaluación de los procesos antrópicos y naturales que inducen la removilización de un campo de dunas sobre la ruta provincial 11, provincia de Buenos Aires, Argentina. GeoFocus (Artículos), Revista Internacional de Ciencia y Tecnología de la Información Geográfica, 27, 135-160. http://dx.doi.org/10.21138/GF.685

de agresiones y a una perturbación tal que afectan de manera considerable a su conservación (Vega de Seoane et al. 2007, Faggi \& Dadon 2010, Marcomini et al. 2011).

Los antecedentes de intervención humana en el sistema costero argentino, en particular, en la Provincia de Buenos Aires, se relacionan al auge del turismo interno de sol y playa a partir del año 1945. Esto dio lugar a la expansión urbana y aparición de una gran cantidad de ciudades balnearias. Se generó de este modo el conocido Corredor Turístico de la Costa Bonaerense (Dadon et al. 2002). Asociadas a este corredor se desarrollaron obras de infraestructura tales como rutas, fijación de médanos, tejidos urbanos, escolleras, etc., que no siempre tuvieron en cuenta la dinámica y vulnerabilidad del ambiente costero. Por esta causa se desencadenaron problemáticas ambientales como retroceso de la línea de acantilado, escasez y contaminación del agua subterránea, erosión costera por desbalances sobre el equilibrio playa/médanos generados por la fijación de médanos (Isla et al. 2001, Marcomini \& Lopez 2008). Por otra parte, la construcción de barreras a la deriva litoral ha favorecido la depositación y erosión en lugares donde no ocurrían de manera natural (Isla 2003).

Los seres humanos se consideran agentes intrínsecos en la evolución de los accidentes geográficos y los paisajes de dunas (Levin et al. 2017). Por otro lado, la utilización de los ambientes naturales para la realización de deportes al aire libre en zonas costeras ha generado impactos ambientales durante su práctica. Una de estas actividades es el tránsito libre de Vehículos Todo Terreno (VTT) por los paisajes litorales como playas y en especial, cuerpos medanosos. Este tipo de vehículos provoca la destrucción de la cubierta vegetal, ocasionando que los sedimentos subyacentes queden expuestos a la removilización por los agentes erosivos al ser desprovistos de la cubierta vegetal que permitía su fijación (Mather y Ritchie 1977, Godfrey y Godfrey 1981, Andersen 1995, Pérez García 2000, Foster-Smith et al. 2007, Hesp et al. 2010).

El proceso de estabilización de las dunas costeras es complejo, e implica mecanismos de retroalimentación y tiempos de retraso entre los cambios en las condiciones climáticas, el establecimiento de la vegetación y el movimiento de las dunas (Levin et al. 2017).

En los cuerpos medanosos la vegetación cumple un rol clave en la génesis y evolución de estas geoformas, por lo que un impacto sobre ésta condicionará de manera directa su desarrollo, reactivándose los procesos de erosión sobre los médanos fijos y semifijos (Vega de Seoane et al. 2007). De este modo aumenta la disponibilidad de sedimentos para el transporte y depositación por los agentes exógenos, condicionando el desarrollo natural del paisaje que termina evolucionando de manera artificial. En muchas ocasiones esta evolución repercute sobre alguna infraestructura socialmente sensible generándose una problemática ambiental.

En la costa atlántica bonaerense es muy frecuente el tránsito de VTT por la playa y médanos costeros, por lo que se encuentra muy impactada y modificada debido a esta actividad (Pérez García 2000, Camino y Padilla 2008). En particular en el sector comprendido entre Mar del Plata y Miramar, el tránsito de VTT sumado a las condiciones climáticas con vientos fuertes, eventos de sudestadas y tormentas intensas (García y Veneciano 2014) dieron lugar a un desbalance de los procesos naturales de erosión y deposición de sedimentos en el cuerpo medanoso (balance sedimentario playa/duna). Esto generó el avance en dirección nornordeste del médano provocando la intrusión de arena sobre sobre la Ruta Provincial 11. Ante una realidad, como la descrita es importante establecer el nivel de degradación ambiental al que está sujeto este ecosistema natural. Para tal motivo, en el caso del impacto antrópico en sistemas costeros, son frecuentes los estudios relacionados a la utilización de imágenes satelitales como 


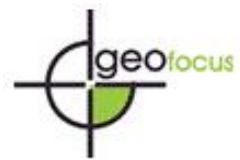

García González, P., Martínez G.A., Alvarez, M.F., Del Río, J.L., Taverna B.D, (2021). Evaluación de los procesos antrópicos y naturales que inducen la removilización de un campo de dunas sobre la ruta provincial 11, provincia de Buenos Aires, Argentina. GeoFocus (Artículos), Revista Internacional de Ciencia y Tecnología de la Información Geográfica, 27, 135-160. http://dx.doi.org/10.21138/GF.685

herramienta de análisis de los procesos generados por dicho impacto (Fadhil 2013, Brownett \& Mills 2017, Levin et al. 2017, Grottoli et al. 2020). A partir de las imágenes se pueden analizar variaciones en las coberturas como movimientos de las dunas y cambios en la línea de costa, entre otros).

El objetivo de este trabajo es evaluar y caracterizar los procesos que dan lugar a la removilización de los sedimentos, que invaden la Ruta Provincial 11 recurrentemente, evaluándose el grado de impacto ambiental que genera el tránsito de VTT por el cuerpo medanoso. A su vez, se busca proponer un plan de manejo que permita aportar soluciones a esta problemática ambiental

\section{Características del área de estudio}

El área de estudio se localiza en la costa atlántica bonaerense, en el sector litoral sur del

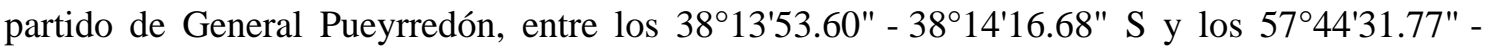
57²5'29.80" W (Fig. 1). Está comprendida entre los barrios de San Eduardo del Mar y El Marquesado, cercanos al límite con el municipio de General Alvarado. Se ubica a unos $9 \mathrm{~km}$ al norte de la ciudad de Miramar y a unos $35 \mathrm{~km}$ al sur de la ciudad de Mar del Plata. Siendo la primera una ciudad que en la actualidad cuenta con una población de unos 30.100 habitantes y la segunda una de las más grandes ciudades del litoral atlántico bonaerense con más de 650.000 habitantes.

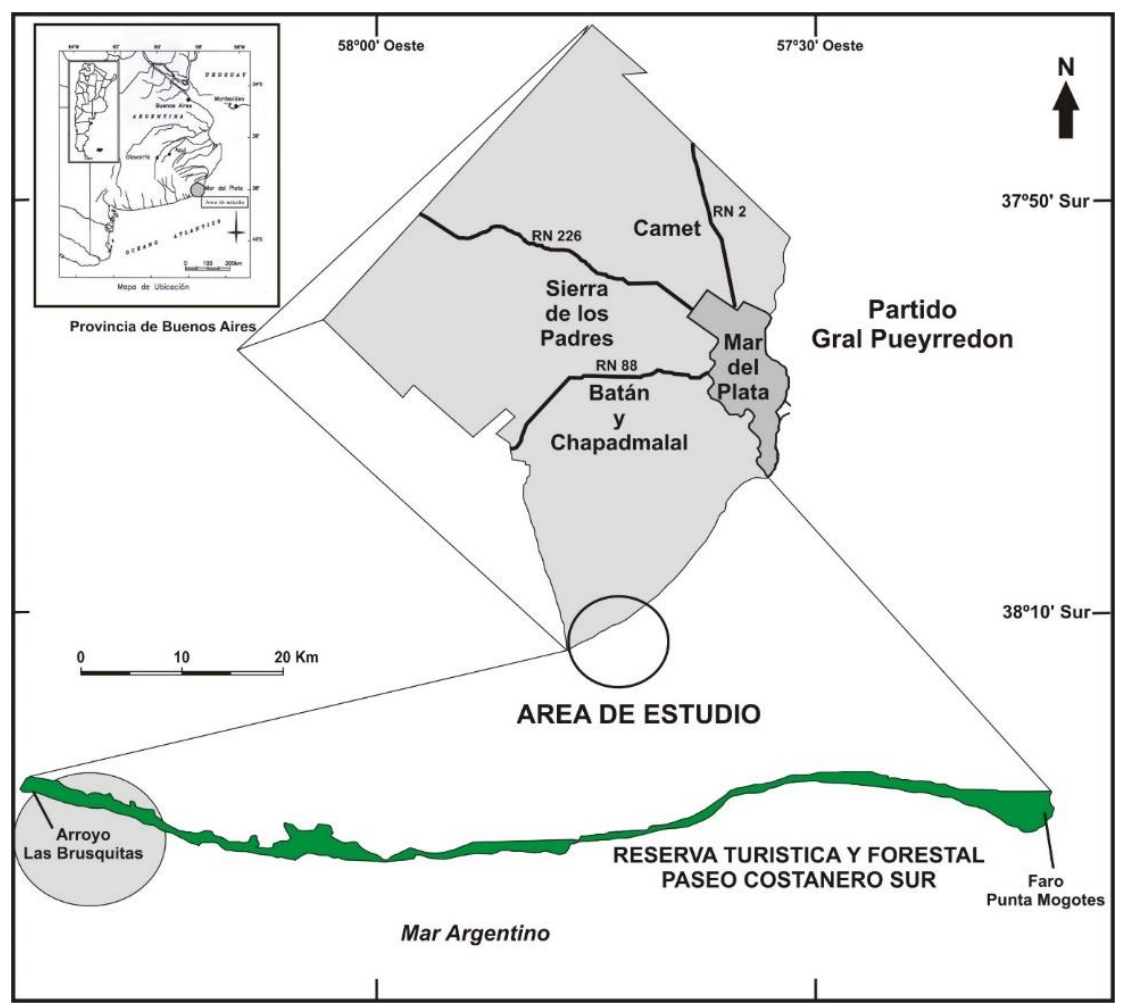

Figura 1. Localización del área de estudio dentro del Municipio de General Pueyrredón. Fte: García y Veneziano, 2005 
García González, P., Martínez G.A., Alvarez, M.F., Del Río, J.L., Taverna B.D, (2021). Evaluación de los procesos antrópicos y naturales que inducen la removilización de un campo de dunas sobre la ruta provincial 11, provincia de Buenos Aires, Argentina. GeoFocus (Artículos), Revista Internacional de Ciencia y Tecnología de la Información Geográfica, 27, 135-160. http://dx.doi.org/10.21138/GF.685

La zona de estudio comprende un cuerpo medanoso de $1,5 \mathrm{~km}$ de longitud y $300 \mathrm{~m}$ de ancho que por su localización está emplazado en el extremo norte de la Barrera Medanosa Austral (BMA) (Isla et al. 2001). En ésta, la acumulación de los sedimentos marinos disponibles se desarrolló sobre la denominada Llanura Interserrana, por lo que la barrera evolucionó adosándose y/o superponiéndose sobre acantilados labrados en sedimentos Plio-Pleistocenos de la denominada Serie Pampeana (Kraglievich 1959, Bonaparte 1960, Zárate \& Fasano 1989, Zavala 1993), de este modo se forman lo que actualmente se conoce como médanos colgados (Marcomini \& López 2005, Isla et al. 2001). Las geoformas que caracterizan este paisaje se ven representadas en las diferentes unidades ambientales de la zona de estudio (García y Veneziano 2005, Bértola \& Merlotto 2010). Entre estas se encuentran las diferentes tipologías de médanos (activos, semifijos y fijos) entre los que se desarrollan rampas eólicas y cuencas de deflación, acantilados (activos e inactivos) y un arroyo que discurre atravesando el cuerpo medanoso $\left(\mathrm{A}^{\circ}\right.$ San Eduardo), el cual corta la continuidad de la línea de acantilado. Ello permitió la formación de una playa en bolsillo (Bértola 2006, García \& Veneziano 2005) de unos $350 \mathrm{~m}$ de longitud, la cual se encuentra en conexión directa con el cuerpo medanoso en la zona central del mismo. De todas estas unidades son los médanos los que presentan mayor variabilidad temporal según su localización respecto a la línea de playa, su cobertura vegetal y su grado de degradación y fragmentación por el tránsito de VTT.

El sector costero donde se ubica el área de estudio corresponde a la Reserva Turística y Forestal Costanera Sur, creada por la Ordenanza Municipal 10011/95, que se extiende desde el Faro Punta Mogotes hasta el arroyo Las Brusquitas, límite sur del Partido de Gral. Pueyrredón con el Partido de General Alvarado. Cuenta con 27 kilómetros de largo y un ancho variable entre 30 y 100 metros hacia el continente y de la ruta hasta la línea de ribera, totalizando una superficie aproximada de 800 ha. Posee rasgos paisajísticos, geológicos, de fauna y flora de especial relevancia, ligados principalmente a la presencia de playas, médanos, acantilados y sectores forestados; todos ellos sometidos a una importante presión antrópica, debido al crecimiento urbano y emprendimientos turísticos-recreativos privados, que se han originado al sur del Partido. En el plan de manejo se establece una zonificación para "optimizar el aprovechamiento de los recursos y permitir la distribución de los usos y actividades" (Witkin et al. 2007). Dentro de esta zonificación el área de estudio queda enmarcada en una zona de conservación dentro de la reserva, pero los propios autores del plan de manejo asumen que "la situación de abandono, falta de interés, de control y de normas" (Witkin et al. 2007), han facilitado que se desarrollen algunas prácticas deportivas y recreativas como el uso de vehículos de doble tracción, pistas de motocross utilizada preponderantemente a lo largo de todo el año por los habitantes de las ciudades de Miramar y Mar del Plata, etc. Estas actividades generan un severo impacto ambiental, más aún en hábitats de conocida fragilidad como es el caso de las dunas costeras (Pérez García 2000, Vega de Seoane et al. 2007). Estas actividades se han potenciado a su vez con el desarrollo socio-económico que ha favorecido en las últimas décadas la aparición de una amplia variedad de modelos de este tipo de vehículos en el mercado automotriz. Estas prácticas deportivas se extendieron de manera acelerada aprovechando un vacío de control por parte del poder de la policía municipal, poniéndose en riesgo la calidad ambiental y la capacidad de las tierras para proporcionar beneficios como hábitats, aguas limpias y lugares para actividades recreativas (Pérez García 2000). 
García González, P., Martínez G.A., Alvarez, M.F., Del Río, J.L., Taverna B.D, (2021). Evaluación de los procesos antrópicos y naturales que inducen la removilización de un campo de dunas sobre la ruta provincial 11, provincia de Buenos Aires, Argentina. GeoFocus (Artículos), Revista Internacional de Ciencia y Tecnología de la Información Geográfica, 27, 135-160. http://dx.doi.org/10.21138/GF.685

\section{Materiales, datos y métodos}

\subsection{Análisis geomorfológico}

La interpretación y descripción geomorfológica del ambiente costero y la de su desarrollo evolutivo se llevó a cabo a partir fotografías aéreas y del análisis de imágenes históricas de Google Earth y relevamientos de campo, desde el año 1977 hasta la actualidad (aunque existe un vacío de información desde 2003 hasta 2011). La imagen aérea del vuelo fotográfico de 1977 fue cedida por la Municipalidad de General Pueyrredón (1/20000, Catastro de MGP), mientras que las imágenes satelitales fueron descargadas del software de libre acceso Google Earth Pro (Copyright Digital Globe 2018) Se seleccionaron, entre el historial de imágenes, las tres más adecuadas para la observación de la zona de estudio y el proceso geomorfológico a analizar. El criterio de selección, se llevó a cabo considerando los siguientes puntos: una clara identificación de la zona de estudio, lapsos mayores a cinco años y fechas de captura similares estacionalmente para poder tener un valor comparativo con condiciones similares. Las fechas seleccionadas fueron: 1997, 31/07/2003, 20/10/2011 y 25/02/2018. Las imágenes de esta sucesión histórica fueron georreferenciadas con el sistema de referencia Campo Inchauspe/Argentina 6 (EPSG:22196) mediante la aplicación de georreferenciación del software Q-Gis. Para ello se utilizaron puntos de referencia homólogos (cruces de carreteras y edificaciones) presentes en la cartografía de referencia y en todas las imágenes de la sucesión histórica.

El área de estudio fue dividida en tres zonas (Norte, Sur y Centro) para su mejor análisis (Fig. 2). En base a la imagen satelital más actualizada se realizó un reconocimiento de las unidades geomorfológicas presentes en las tres zonas, mediante un análisis visual y observaciones de campo. De este modo se realizó una categorización geomorfológica de las diferentes zonas, usando puntos de verificación en el terreno mediante GPS. Esto se plasmó en un mapa geomorfológico general para la zona de estudio digitalizando de forma manual las diferentes unidades geomorfológicas observadas. Basándose en este mapa geomorfológico que representa el estado actual, las observaciones de campo, los puntos de verificación GPS y el conocimiento del área de estudio se realizó para cada imagen de la sucesión histórica una categorización geomorfológica simplificada delimitando polígonos correspondientes a las geoformas médano fijo, semifijo y activo, playa, acantilado y arroyo. Luego, en cada una de las imágenes de la sucesión histórica se digitalizaron manualmente los caminos marcados por el tránsito de vehículos que eran fácilmente reconocibles, la cresta del médano activo en la zona norte de estudio y el borde del acantilado.

Para evaluar de forma cuantitativa la evolución del paisaje se realizaron gráficas de la superficie ocupada por cada una de las unidades geomorfológicas mediante la medición de áreas con el software Q-Gis. De este modo, se pudo comparar gráficamente la evolución del paisaje entre los diferentes estados temporales en los diferentes sectores.

A los fines de determinar la presión de uso se elaboró un indicador basado en la densidad relativa de caminos o sendas en cada polígono. Así, para analizar el impacto del tránsito de VTT sobre el ambiente se utilizó la densidad de caminos como geoindicador o indicador ambiental de presión según lo propuesto por Camino et al. (2001) y del Río et al. (2016). Este valor se obtiene de la relación entre la distancia recorrida total por los caminos digitalizados por unidad de superficie de cada zona $(\mathrm{m} / \mathrm{ha})$. 
García González, P., Martínez G.A., Alvarez, M.F., Del Río, J.L., Taverna B.D, (2021). Evaluación de los procesos antrópicos y naturales que inducen la removilización de un campo de dunas sobre la ruta provincial 11, provincia de Buenos Aires, Argentina. GeoFocus (Artículos), Revista Internacional de Ciencia y Tecnología de la Información Geográfica, 27, 135-160. http://dx.doi.org/10.21138/GF.685

Mediante el software AutoCAD se estudió el retroceso del borde del acantilado y el avance de la cresta del médano activo hacia la Ruta Provincial 11, realizándose mediciones de distancias y direcciones de avance, así como el análisis de la evolución de la cuenca de deflación generada por la removilización del médano activo.

Por último, se reconocieron eventos de avance de la duna sobre la carretera en imágenes satelitales entre las fechas aquí analizadas, las cuales ayudaron a la interpretación de la evolución del paisaje.

\subsection{Análisis de vegetación y sedimentos}

Se realizaron varios censos de vegetación en aquellas unidades ambientales representativas. Los relevamientos de las especies vegetales se realizaron utilizando cuadrantes de $1 \mathrm{~m}$ x $1 \mathrm{~m}$ ubicados al azar dentro de cada unidad (Matteucci \& Colma 1982). Para la estimación de la cobertura vegetal se utilizó un modelo derivado de Braun Blanquet (1932), donde el cuadrante de $1 \mathrm{~m} \times 1 \mathrm{~m}$ se dividió en 100 unidades y se contabilizó la cantidad de cuadrantes que se observaron cubiertos. Se determinaron las especies presentes (Cabrera 1941), estimándose cobertura específica de las más representativas. Aquellas especies no reconocidas in situ fueron muestreadas y llevadas al laboratorio para su posterior determinación mediante claves dicotómicas bajo lupa binocular.

En cada unidad ambiental asociada a los censos de vegetación, se recolectaron muestras de suelos y sedimentos para su determinación granulométrica y de materia orgánica. Se calcularon los parámetros de tamaño de grano (Folk \& Ward 1957) como tamaño de grano, mediana, desviación estándar, asimetría y curtosis, mediante el software GradiStat v.8 (Blott y Pie 2008). La determinación de la materia orgánica se realizó por el método de oxidación (Walkey \& Black 1965).

\section{Resultados}

La zona de estudio se caracteriza por presentar un paisaje poligenético conformado por procesos marinos, antrópicos, eólicos y fluviales. En aquellas zonas donde las condiciones del sustrato arenoso son más dinámicas y varían en el tiempo por la acción del mar y el viento, como en la playa distal y en los médanos activos, la cobertura vegetal es baja, y caracterizada por géneros vegetales adaptados para sobrevivir en estas condiciones. Al internarse hacia el continente, en los médanos fijos, donde las condiciones del sustrato son más estables y la incidencia del viento y spray marino es menor, estos presentan mayor cobertura y diversidad vegetal como consecuencia de la estabilidad ambiental. Ello permite un mayor grado de biodiversidad producto de la sucesión ecológica. La evolución de las geoformas está condicionada por la dinámica de erosión/deposición de los sedimentos, la cobertura vegetal que se desarrolla según el grado de sucesión ecológica y el impacto antrópico (representado por el indicador densidad de caminos). 


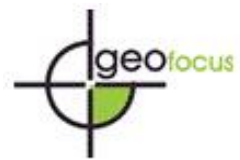

García González, P., Martínez G.A., Alvarez, M.F., Del Río, J.L., Taverna B.D, (2021). Evaluación de los procesos antrópicos y naturales que inducen la removilización de un campo de dunas sobre la ruta provincial 11, provincia de Buenos Aires, Argentina. GeoFocus (Artículos), Revista Internacional de Ciencia y Tecnología de la Información Geográfica, 27, 135-160. http://dx.doi.org/10.21138/GF.685

\subsection{Evolución temporal del paisaje}

La caracterización ambiental de la zona de estudio se realizó basándose en las observaciones de los relevamientos de campo y el análisis de las imágenes satelitales. Para cada imagen se digitalizaron los principales rasgos geomorfológicos y el grado de cobertura vegetal (Fig. 2). Entre estos se digitalizó el borde del acantilado, el cauce del arroyo San Eduardo, los límites de la playa, la parte alta del médano activo (cresta) y las coberturas vegetales definidas en tres categorías: vegetado (cobertura total $\geq 60 \%$ ), incipiente (cobertura total $\leq 60 \%$ ) y no vegetado (cobertura total $\leq 5 \%$ ) (Fig. 3). Estos se relacionan con las unidades geomorfológicas: médano fijo, médano semifijo y médano activo o migrante (Fig. 2). Este último es el que ha sido objeto de distintas intervenciones por ser el que obstruye la Ruta Provincial 11.

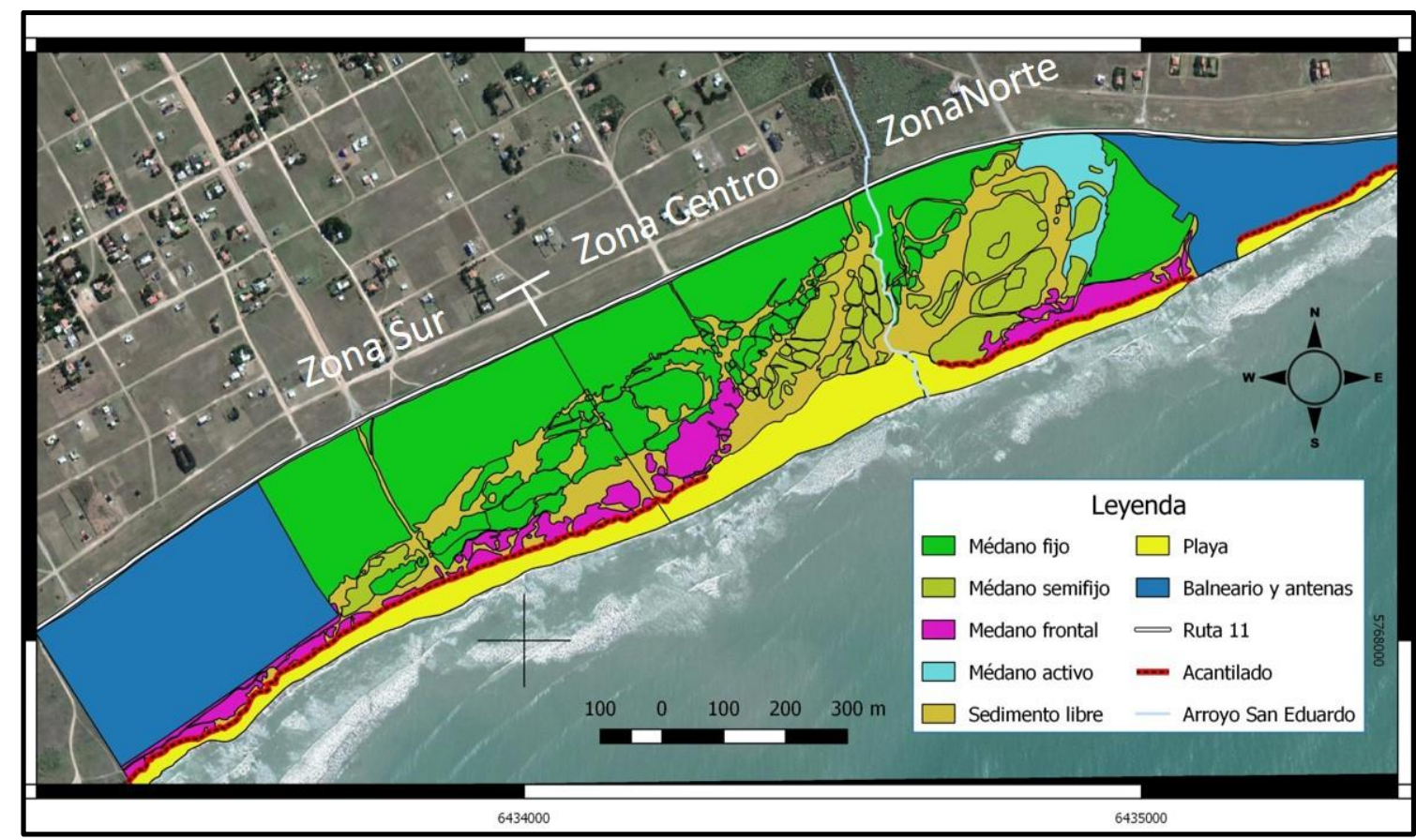

Figura 2. Mapa geomorfológico del área de estudio. Sectores delimitados en función de su cobertura vegetal y ubicación. Año: 2018

Fte.: Imagen Google Earth. 


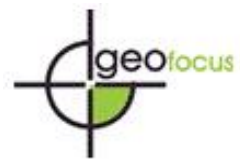

García González, P., Martínez G.A., Alvarez, M.F., Del Río, J.L., Taverna B.D, (2021). Evaluación de los procesos antrópicos y naturales que inducen la removilización de un campo de dunas sobre la ruta provincial 11, provincia de Buenos Aires, Argentina. GeoFocus (Artículos), Revista Internacional de Ciencia y Tecnología de la Información Geográfica, 27, 135-160. http://dx.doi.org/10.21138/GF.685

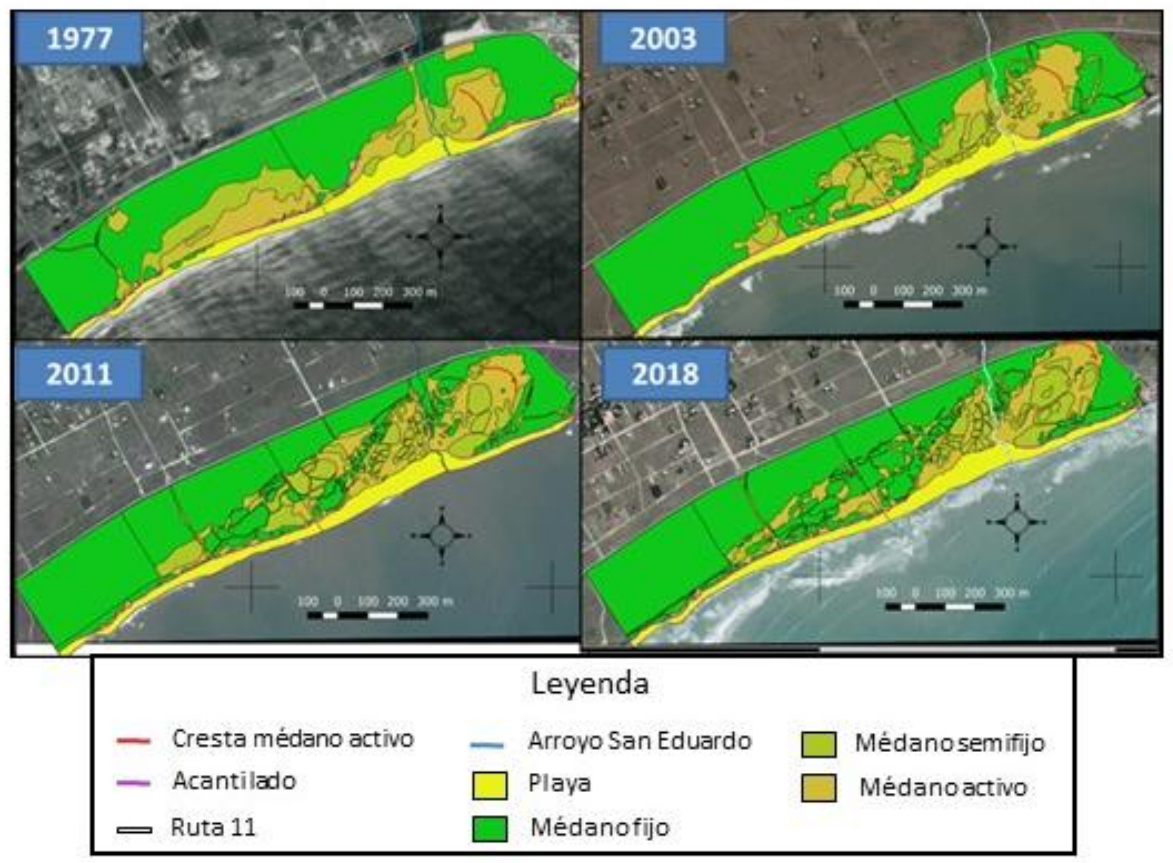

Figura 3: Mapas geomorfológicos del área de estudio para cada corte temporal Fte.: Imágenes de la Municipalidad de General Pueyrredón y Google Earth.

Teniendo en cuenta las áreas ocupadas por cada tipología de médano, se comparó el desarrollo evolutivo de cada una de ellas, a lo largo del periodo de estudio, en cada una de las zonas: Sur, Norte y Centro.

En la Zona Sur la evolución temporal de los médanos tiene una tendencia al aumento de la superficie cubierta por médanos fijos, reduciéndose, por ende, la superficie de médanos semifijos y activos (Fig. 4 A). En la Zona Centro la tendencia se invierte, así la superficie cubierta por médanos fijos se va reduciendo con los años para pasar a estar cubiertos por médanos semifijos principalmente. A pesar de esto, en el último corte temporal (2018) la tendencia vuelve a invertirse, pero sin llegar a revertir los valores iniciales. La superficie cubierta por médanos activos no varía mucho en la evolución temporal de esta zona (Fig. 4 B). En la Zona Norte la tendencia es de reducción de la superficie cubierta por médanos fijos. Estas superficies pasan a ser cubiertas por médanos semifijos y activos o migrante (Fig. 4 C). Existe un cambio en la dinámica sedimentaria similar al de la Zona Sur por la reducción del sedimento disponible en la playa, a pesar de lo cual en el extremo sur se mantiene una conexión con la playa. Las rampas de transporte eólico labradas en el sustrato Pampeano favorecen la movilidad de los sedimentos desde la playa y la desembocadura del arroyo hacia la porción distal del cuerpo medanoso. Sumado a esto, la Zona Norte se ve altamente impactada desde 1977 a 2011, lo que se ve reflejado en una reducción de la cobertura vegetal $(30-50 \%,<10 \%$ en N.5) y de la superficie cubierta por médanos fijos (Fig. 4 C). 


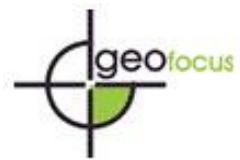

García González, P., Martínez G.A., Alvarez, M.F., Del Río, J.L., Taverna B.D, (2021). Evaluación de los procesos antrópicos y naturales que inducen la removilización de un campo de dunas sobre la ruta provincial 11, provincia de Buenos Aires, Argentina. GeoFocus (Artículos), Revista Internacional de Ciencia y Tecnología de la Información Geográfica, 27, 135-160. http://dx.doi.org/10.21138/GF.685
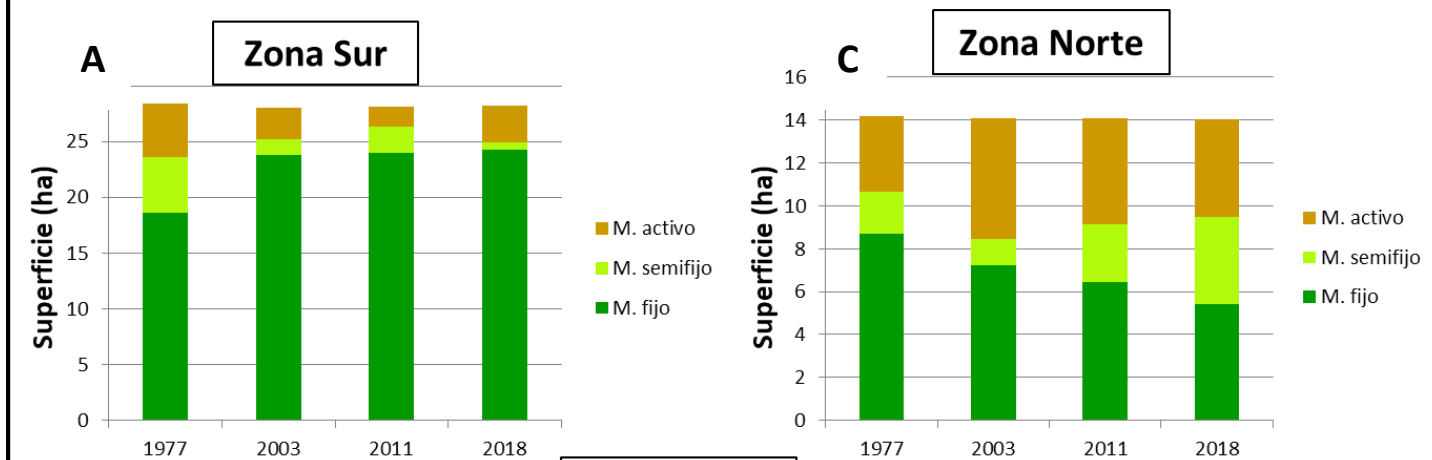

Zona Centro

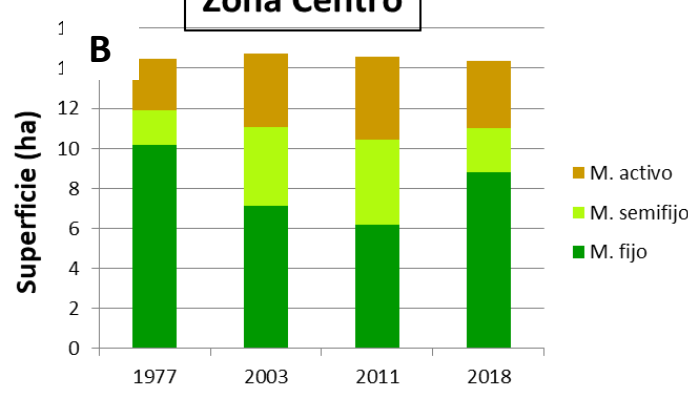

Figura 4. Comparación entre los cortes temporales de las superficies ocupadas por los tres tipos de médanos en función de su actividad y cobertura vegetal. A: Zona Sur, B: Zona Centro y C: Zona Norte.

\subsection{Granulometría y materia orgánica}

El análisis granulométrico de las arenas del médano, indica que la media, según el método gráfico de Folk \& Ward (1957), varía de 1,270 $\phi$ a 2,264 $\phi$, por lo que las muestras son de arena de grano fino a medio según la clasificación de Wentworth (1929) (Tabla 1). Los valores de la desviación estándar varían de 0,474 $\phi$ a $0,803 \phi$, por lo tanto, las muestras son bien clasificadas a moderadamente clasificadas (Tabla 1). La asimetría varía de $-0,131 \phi$ a 0,051 $\phi$, pero solo una de ellas (S. 3) tiene asimetría gruesa, siendo el resto simétricas (Tabla 1). Los valores de curtosis van de 0,995 $\phi$ a 1,117 $\phi$. Las distribuciones de tamaño de grano son todas mesocúrticas, excepto la muestra C. 2 que es leptocúrtica (Tabla 1).

Los valores de materia orgánica variaron entre 0,4 y $2,4 \%$. Los mayores valores se observaron en C.2 que registró un 2,38 \%, S.3 un 0,9\% y N.3 un 0,86 \% (Tabla 1). 


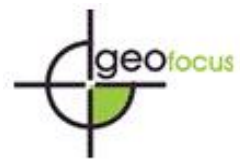

García González, P., Martínez G.A., Alvarez, M.F., Del Río, J.L., Taverna B.D, (2021). Evaluación de los procesos antrópicos y naturales que inducen la removilización de un campo de dunas sobre la ruta provincial 11, provincia de Buenos Aires, Argentina. GeoFocus (Artículos), Revista Internacional de Ciencia y Tecnología de la Información Geográfica, 27, 135-160. http://dx.doi.org/10.21138/GF.685

Tabla 1. Valores de los parámetros y datos estadísticos granulométricos (Folk \& Ward, 1957) y datos de materia orgánica (Walkey \& Black, 1965) en los sitios estudiados. Zona Norte: N. 1: "Cuenca de drenaje perfil profundo", N. 2: "Parte frontal médano vivo", $N$. 3: "Médano fijo", N. 4: "Cuenca de drenaje perfil somero". Zona Centro: C. 2: "Médano frontal parte media". Zona Sur: S. 1: "Zona alta médanos fragmentados", S. 2: "Parte baja blow-out no vegetado", S. 3: "Bajo interdunas desarrollado", S. 4: "Bajo interdunas incipiente".

\begin{tabular}{|c|c|c|c|c|c|c|c|c|c|c|}
\hline \multirow[t]{2}{*}{ Muestra } & \multirow{2}{*}{$\begin{array}{l}\text { Mediana } \\
(\phi)\end{array}$} & \multirow{2}{*}{$\begin{array}{l}\text { Media } \\
(\phi)\end{array}$} & \multicolumn{2}{|c|}{ Desviación estándar } & \multicolumn{2}{|c|}{ Asimetría } & \multicolumn{2}{|c|}{ Curtosis } & \multirow{2}{*}{$\begin{array}{c}\text { Tipo de } \\
\text { sedimento }\end{array}$} & \multirow{2}{*}{$\begin{array}{c}\text { Materia } \\
\text { orgánica } \\
(\%)\end{array}$} \\
\hline & & & $\begin{array}{c}\text { Valor } \\
(\phi)\end{array}$ & Clase & $\begin{array}{l}\text { Valor } \\
(\phi)\end{array}$ & Clase & $\begin{array}{l}\text { Valor } \\
(\phi)\end{array}$ & Clase & & \\
\hline N. 1 & 1,253 & 1,270 & 0,803 & $\begin{array}{l}\text { Moderadamente } \\
\text { clasificado }\end{array}$ & 0,051 & Simétrica & 0,998 & Mesocúrtica & $\begin{array}{l}\text { Arena } \\
\text { media }\end{array}$ & 0,41 \\
\hline N. 2 & 1,845 & 1,835 & 0,596 & $\begin{array}{l}\text { Moderadamente } \\
\text { bien clasificado }\end{array}$ & 0,002 & Simétrica & 1,002 & Mesocúrtica & $\begin{array}{l}\text { Arena } \\
\text { media }\end{array}$ & 0,37 \\
\hline N. 3 & 1,885 & 1,868 & 0,706 & $\begin{array}{l}\text { Moderadamente } \\
\text { clasificado }\end{array}$ & $-0,057$ & Simétrica & 1,077 & Mesocúrtica & $\begin{array}{l}\text { Arena } \\
\text { media }\end{array}$ & 0,86 \\
\hline N. 4 & 1,987 & 1,983 & 0,509 & $\begin{array}{l}\text { Moderadamente } \\
\text { bien clasificado }\end{array}$ & 0,013 & Simétrica & 1,055 & Mesocúrtica & $\begin{array}{l}\text { Arena } \\
\text { media }\end{array}$ & 0,45 \\
\hline C. 2 & 2,195 & 2,195 & 0,523 & $\begin{array}{l}\text { Moderadamente } \\
\text { bien clasificado }\end{array}$ & $-0,006$ & Simétrica & 1,117 & Leptocúrtica & $\begin{array}{l}\text { Arena } \\
\text { fina }\end{array}$ & 2,38 \\
\hline S. 1 & 2,261 & 2,264 & 0,474 & Bien clasificado & $-0,006$ & Simétrica & 1,077 & Mesocúrtica & $\begin{array}{l}\text { Arena } \\
\text { fina }\end{array}$ & 0,55 \\
\hline S. 2 & 2,246 & 2,252 & 0,498 & Bien clasificado & 0,033 & Simétrica & 1,02 & Mesocúrtica & $\begin{array}{l}\text { Arena } \\
\text { fina }\end{array}$ & 0,45 \\
\hline S. 3 & 1,996 & 1,928 & 0,607 & $\begin{array}{l}\text { Moderadamente } \\
\text { bien clasificado }\end{array}$ & $-0,131$ & $\begin{array}{l}\text { Asimetría } \\
\text { gruesa }\end{array}$ & 1,016 & Mesocúrtica & $\begin{array}{l}\text { Arena } \\
\text { media }\end{array}$ & 0,90 \\
\hline S. 4 & 1,962 & 1,931 & 0,549 & $\begin{array}{l}\text { Moderadamente } \\
\text { bien clasificado }\end{array}$ & $-0,038$ & Simétrica & 0,995 & Mesocúrtica & $\begin{array}{l}\text { Arena } \\
\text { media }\end{array}$ & 0,50 \\
\hline
\end{tabular}

\subsection{Cobertura Vegetal}

La cobertura total varió en función de la unidad ambiental/geomorfológica (Fig. 5), registrándose los mayores porcentajes de cobertura en las unidades de vegetación que se desarrollan en unidades geomorfológicas definidas como médanos fijos (cobertura vegetal total entre 60 a $100 \%$ ). Mientras que se observó una menor cobertura total en las unidades de vegetación desarrolladas sobre los médanos semifijos (cobertura vegetal total entre 5 a $60 \%$ ).

Se registraron en toda el área de estudio un total de 26 especies vegetales, distribuidas en 7 familias: Asteraceae (11), Poaceae (7), Fabaceae (3), Apiaceae (2), Brassicaceae (1), Calyceraceae (1) y Onagraceae (1). Las especies más recurrentes en todas las zonas fueron Sporobolus coarctatus, Hydrocotyle bonariensis y Carpobrotus edulis.

Teniendo en cuenta el status de las especies determinadas en toda el área del cuerpo medanoso el 61,54 \% son nativas para el Cono Sur y el 38,46 \% son exóticas. Cabe destacar que 


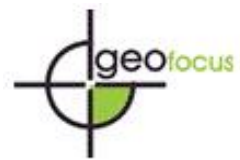

García González, P., Martínez G.A., Alvarez, M.F., Del Río, J.L., Taverna B.D, (2021). Evaluación de los procesos antrópicos y naturales que inducen la removilización de un campo de dunas sobre la ruta provincial 11, provincia de Buenos Aires, Argentina. GeoFocus (Artículos), Revista Internacional de Ciencia y Tecnología de la Información Geográfica, 27, 135-160. http://dx.doi.org/10.21138/GF.685

las especies relevadas fueron todas herbáceas, sin embargo, se pudieron observar algunos arbustos aislados de Baccharis sp. en algunos bajos de interdunas.

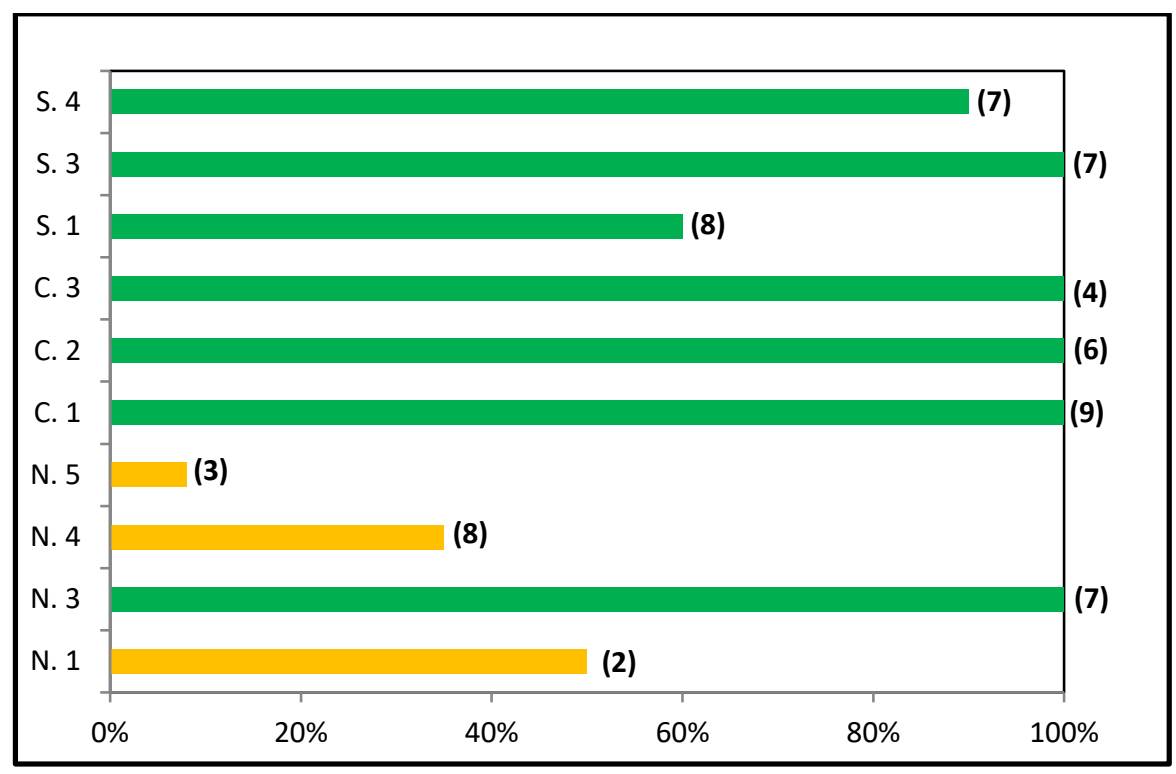

Figura 5: Porcentaje de cobertura total entre las unidades de vegetación reconocidas.

Verde: unidades desarrolladas sobre médanos fijos (60 a $100 \%)$. Amarillo: unidades desarrolladas sobre médanos semifijos (5 a $60 \%$ ). (). número de especies reconocidas en los censos. Zona Sur: S. 4: "Bajo interdunas incipiente", S. 3: "Bajo interdunas desarrollado", S. 1:

"Zona alta médanos fragmentados". Zona Centro: C. 3: "Médano frontal parte alta", C. 2: "Médano frontal parte media", C. 1: "Médano frontal parte baja". Zona Norte: N. 5: "Cuenca de drenaje Pampeano expuesto", N. 4: "Cuenca de drenaje perfil somero", N. 3: "Médano fijo", N. 1: "Cuenca de drenaje perfil profundo".

\subsection{Alteración antrópica por desarrollo de sendas y de caminos}

Se observó un incremento en la cantidad de caminos y sendas en las tres zonas entre el año 1977 hasta la actualidad. En la Zona Norte el desarrollo de caminos comenzó antes que en las otras dos zonas, desde el 2003. En el año 2011 si bien las tres zonas sufrieron un aumento del impacto de las sendas y caminos, esta situación se agudiza principalmente la Zona Centro. Después de este año decrece en las tres zonas, aunque nuevamente es más significativo para la Zona Centro (Fig. 6) por una consolidación de las sendas por un uso reiterado. En los relevamientos de campo se pudo comprobar que el desarrollo de estas sendas y caminos sobre las geoformas y su dinámica natural provocaron un paisaje fragmentado en forma de parches geométricos y separados por los caminos. Estos parches son retrabajados por acción de los agentes naturales (agua y viento), en algunos casos son erosionados todos los sedimentos que conformaban los médanos hasta dejar expuesto del sustrato Pampeano (Fig. 7). 
García González, P., Martínez G.A., Alvarez, M.F., Del Río, J.L., Taverna B.D, (2021). Evaluación de los procesos antrópicos y naturales que inducen la removilización de un campo de dunas sobre la ruta provincial 11, provincia de Buenos Aires, Argentina. GeoFocus (Artículos), Revista Internacional de Ciencia y Tecnología de la Información Geográfica, 27, 135-160. http://dx.doi.org/10.21138/GF.685

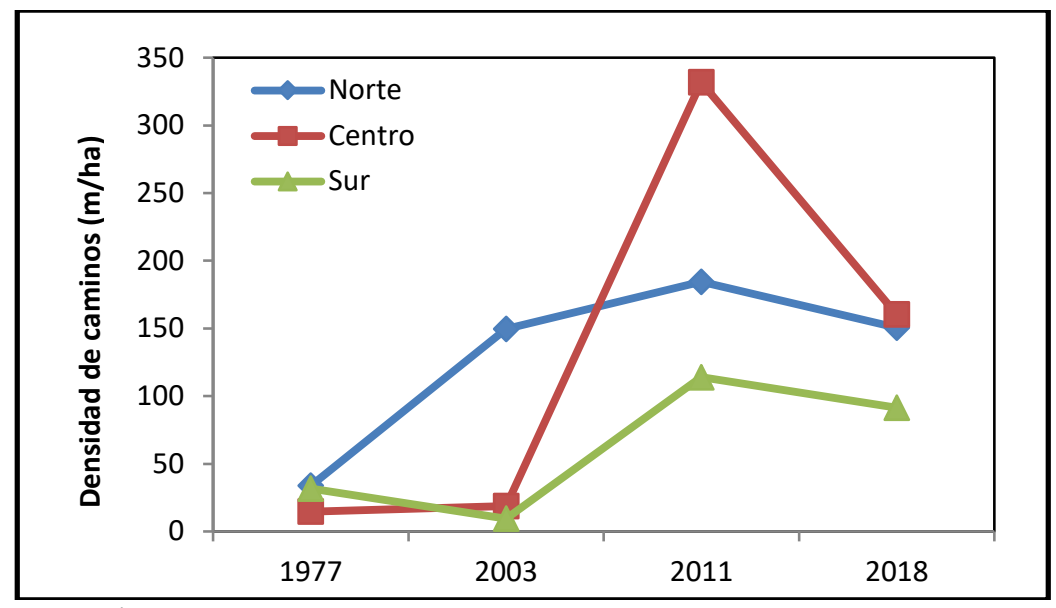

Figura 6. Variación de la densidad de caminos a lo largo del tiempo para las tres zonas estudiadas.

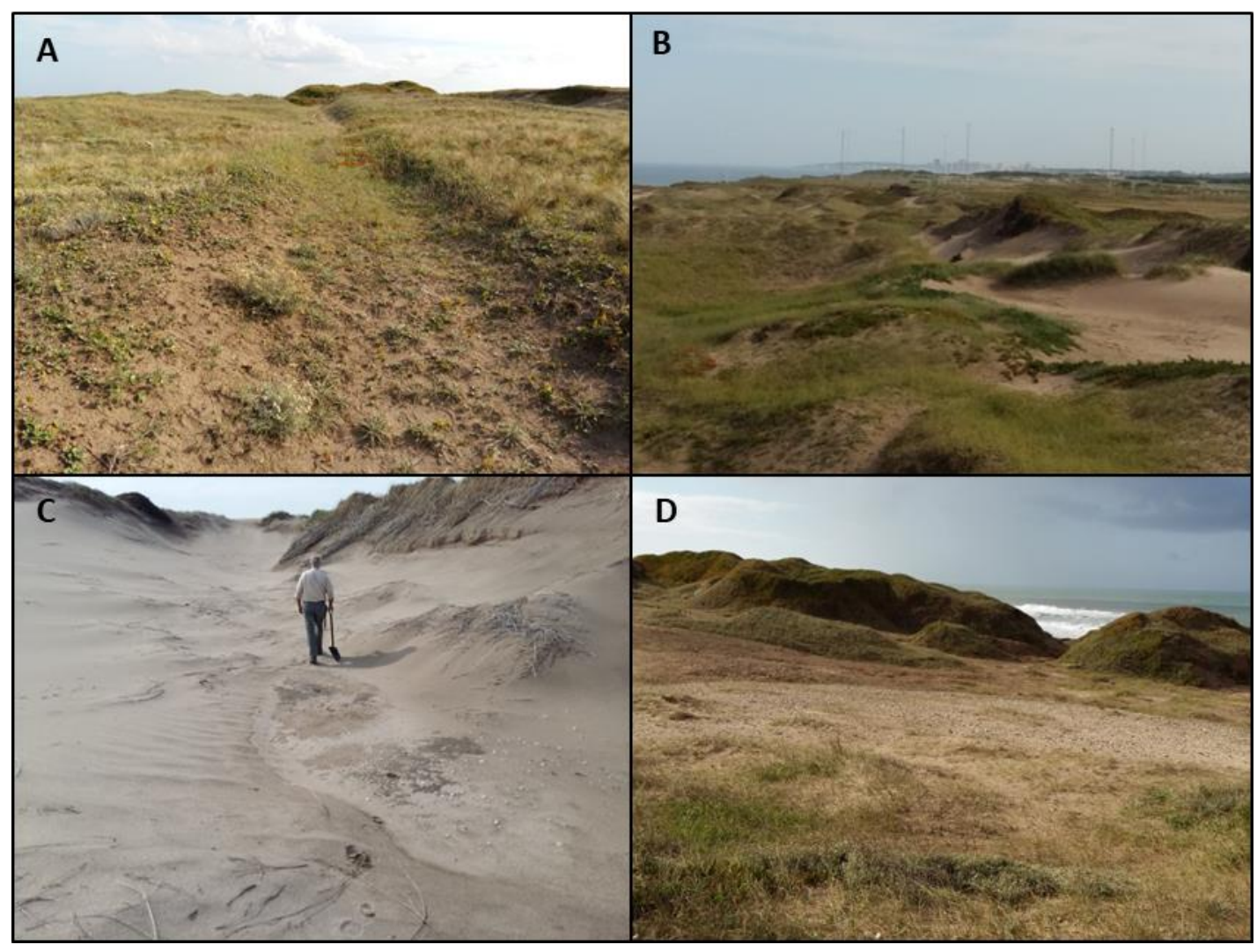

Figura 7. Imágenes representativas del impacto por el tránsito de VTT. A: Médano fijo impactado por el tránsito de VTT, B: Estado de fragmentación de los médanos, aislados por caminos y corredores de arena, C: Corredor de arena cuyo sustrato ha sido erosionado hasta llegar al límite del sustrato Pampeano y D: Médanos frontales aislados en el borde del acantilado en la Zona Sur. 


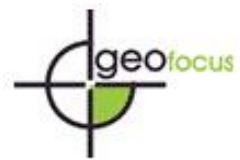

García González, P., Martínez G.A., Alvarez, M.F., Del Río, J.L., Taverna B.D, (2021). Evaluación de los procesos antrópicos y naturales que inducen la removilización de un campo de dunas sobre la ruta provincial 11, provincia de Buenos Aires, Argentina. GeoFocus (Artículos), Revista Internacional de Ciencia y Tecnología de la Información Geográfica, 27, 135-160. http://dx.doi.org/10.21138/GF.685

\subsection{Avance del frente de médano activo}

En la porción nororiental de la Zona Norte, se mapeo la presencia del médano activo de aspecto parabólico que avanza en dirección NNE y que en ocasiones ocupa parcial o totalmente la Ruta Provincial 11 (Fig. 8 y 9 A). Para evaluar el avance neto y la dirección de éste, se digitalizó la cresta del médano activo, y fijo su posición entre los cortes temporales consecutivos (Tabla 2).

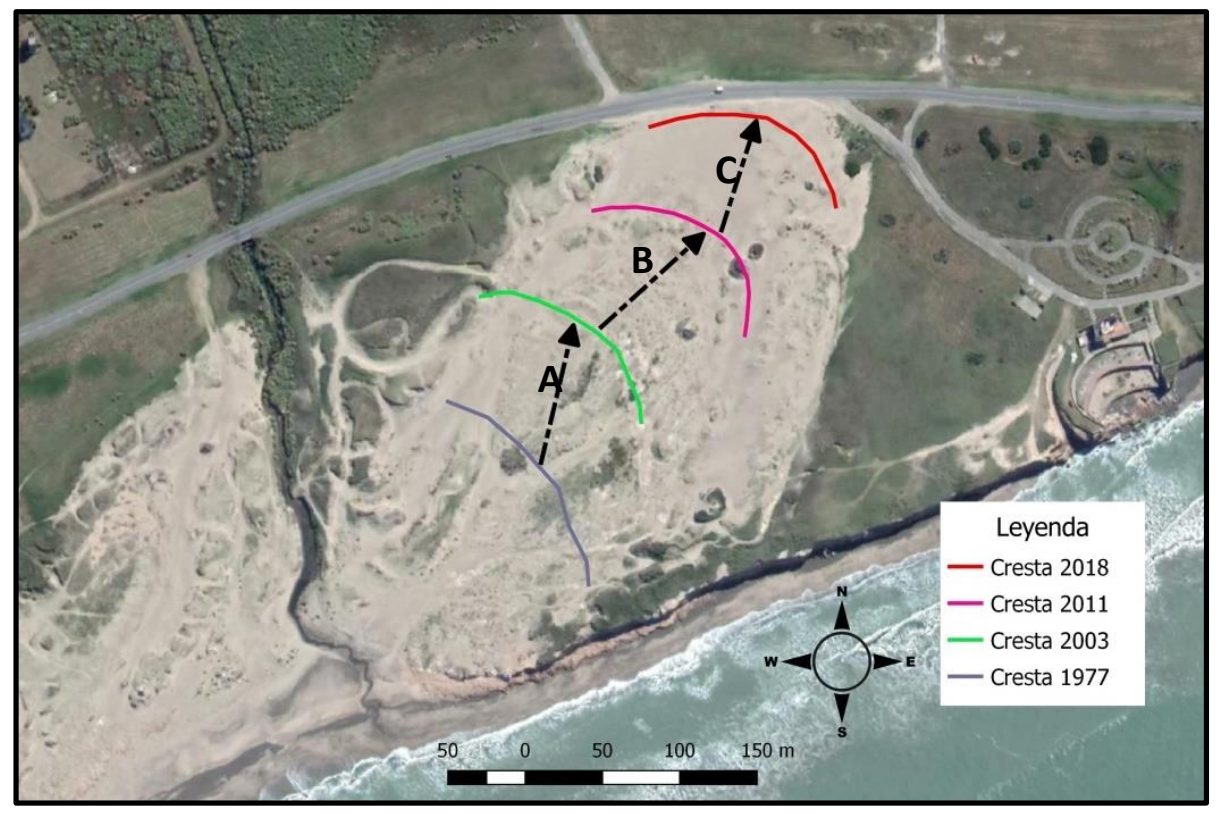

Figura 8. Crestas del médano activo digitalizadas en cada corte temporal montadas sobre la imagen satelital de 2018. Dirección de avance de la cresta del médano vivo A: primer lapso temporal, B: segundo lapso temporal y C: tercer lapso temporal.

Tabla 2. Avance medio y tasa de avance anual de la cresta del médano vivo en los tres lapsos temporales.

\begin{tabular}{|l|c|c|}
\hline & Avance medio (m) & Tasa de avance anual (m/año) \\
\hline $1977 / 2003$ & 97,14 & 3,74 \\
\hline $2003 / 2011$ & 96,77 & 12,10 \\
\hline $2011 / 2018$ & 80,64 & 11,52 \\
\hline
\end{tabular}

Se observó una mayor velocidad de avance en los últimos cortes temporales, con respecto del primero. Se debe tener en cuenta para la interpretación de la complejidad ambiental que el médano se encuentra en el borde de la ruta y este es un límite de avance artificial, debido a la intervención constante del ente de Vialidad Municipal para despejar la cinta asfáltica. 


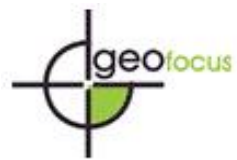

García González, P., Martínez G.A., Alvarez, M.F., Del Río, J.L., Taverna B.D, (2021). Evaluación de los procesos antrópicos y naturales que inducen la removilización de un campo de dunas sobre la ruta provincial 11, provincia de Buenos Aires, Argentina. GeoFocus (Artículos), Revista Internacional de Ciencia y Tecnología de la Información Geográfica, 27, 135-160. http://dx.doi.org/10.21138/GF.685

La dirección de avance varió poco en función de los cortes temporales, Nor-nordeste para el primer y tercer corte temporal (1977/2003 y 2011/2018), mientras que el segundo corte temporal (2003/2011) tiene dirección Noreste (Fig. 8).

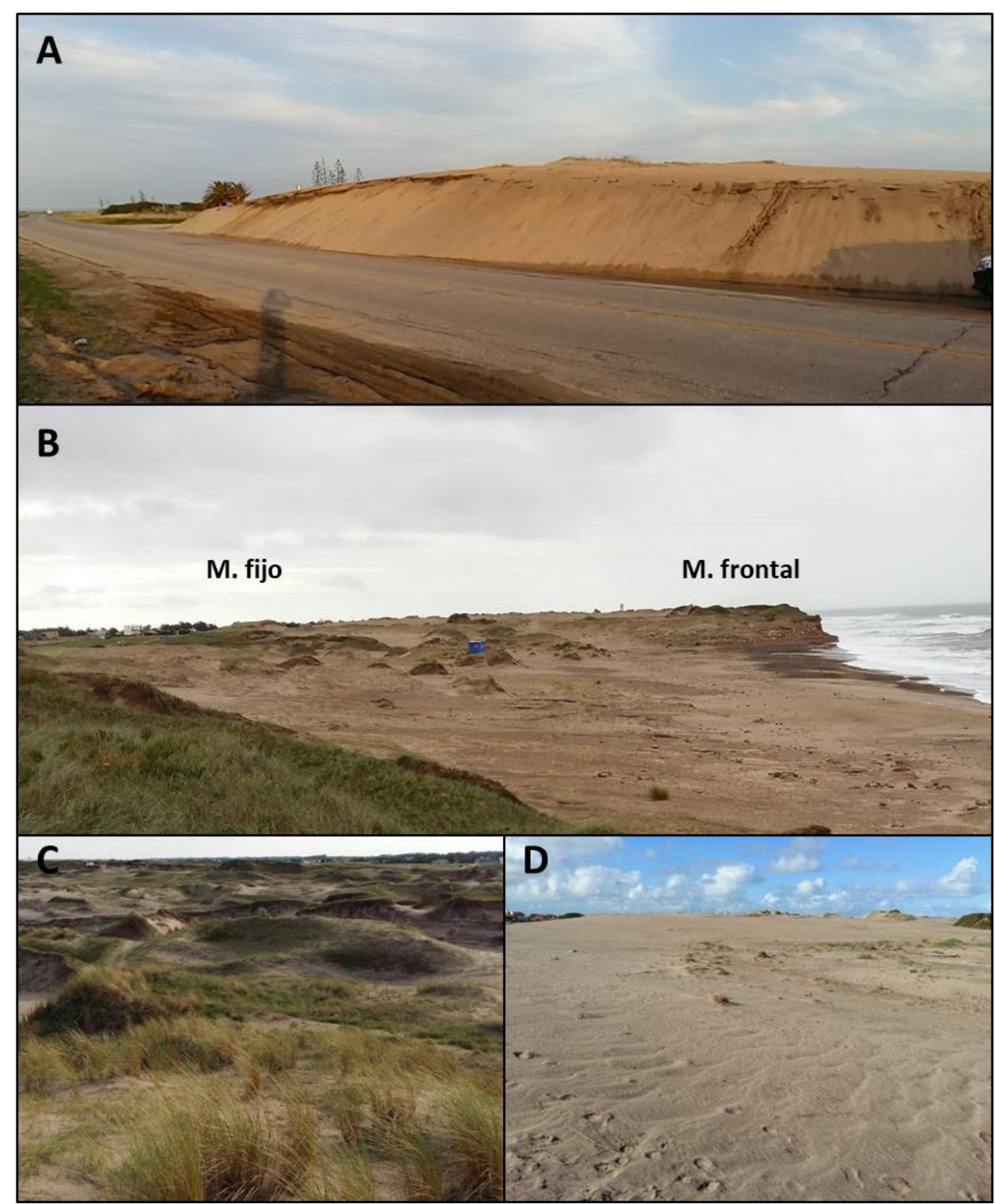

Figura 9.Imágenes representativas del paisaje de la Zona Norte. A: Cara de barlovento del médano vivo, en el límite de la Ruta Provincial 11, B: Fotografía panorámica de la Zona Norte, se observa la cuenca de deflación que genera el avance del médano vivo, separando el médano fijo posterior del médano frontal, C: Médanos semifijos fragmentados por los caminos y el tránsito de VTT y D: Médano vivo en su cara de sotavento

En esta cuenca de deflación se alternan parches de vegetación incipiente que acumulan arenas eólicas (médanos semifijos), con otros desprovisto de cubierta vegetal y con un sustrato 


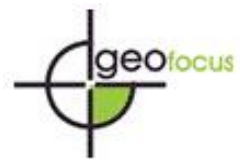

García González, P., Martínez G.A., Alvarez, M.F., Del Río, J.L., Taverna B.D, (2021). Evaluación de los procesos antrópicos y naturales que inducen la removilización de un campo de dunas sobre la ruta provincial 11, provincia de Buenos Aires, Argentina. GeoFocus (Artículos), Revista Internacional de Ciencia y Tecnología de la Información Geográfica, 27, 135-160. http://dx.doi.org/10.21138/GF.685

Pampeano expuesto (Fig. 9 C y D). Por estos motivos, la superficie total de esta cuenca se analizó de manera más exhaustiva. Para entender su desarrollo evolutivo se digitalizó su perímetro y los parches de vegetación incipiente que se desarrollaban sobre la misma. De este modo se calculó para cada corte temporal la superficie total, diferenciándose aquella superficie desprovista de cubierta vegetal (libre) de la que presenta vegetación incipiente (médanos semifijos) (Fig. 10).

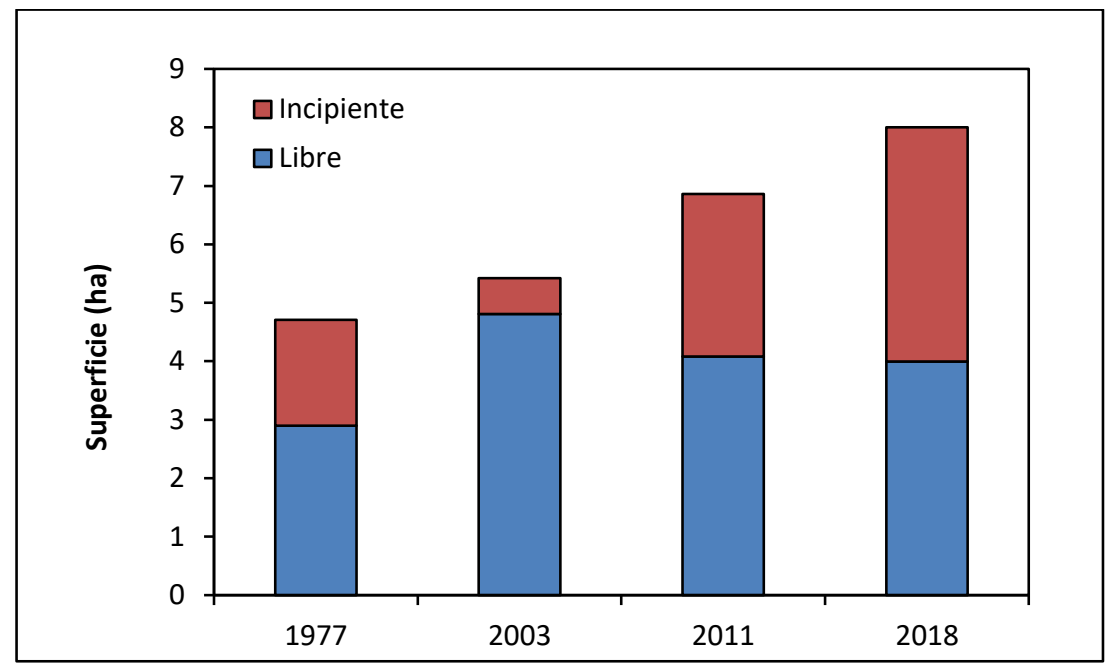

Figura 10. Superficie ocupada por la cuenca de deflación que se forma por el avance del médano activo. Para cada corte temporal se muestra la superficie de esta que corresponde a sedimentos desprovistos de cubierta vegetal (Libre) y la que corresponde a parches de vegetación incipiente, médanos semifijos (Incipiente).

Debido al avance del médano activo, se pudo observar una tendencia al aumento de la superficie total de esta cuenca de deflación. Esta tendencia fue mayor en los últimos cortes temporales por la mayor tasa de avance del médano activo. A pesar de esto, el incremento de la superficie con sedimentos libres es menor que la ocupada por la vegetación incipiente. la superficie con sedimentos libres no aumenta tanto como la ocupada por la vegetación incipiente.

\subsection{Retroceso del acantilado}

El análisis de las imágenes mostró una variación en la morfología de la playa y la erosión del acantilado en algunas zonas. El proceso de digitalización del borde del acantilado se dificultó por las diferencias de paralaje entre imágenes, sombras en las imágenes y morfologías diferentes, lo cual se tuvo que tener en cuenta en la interpretación.

El área ocupada por la playa en las tres zonas no varió significativamente a lo largo del tiempo, pero se observó un cambio en su morfología en la fotografía aérea de 1977 (Fig. 3). En ésta, se pone de relieve la discontinuidad del borde del acantilado en la Zona Sur por la presencia de arena acumulada, la cual funciona como rampa eólica, conectándose el tránsito de sedimentos entre la playa y el médano colgado sobre el acantilado. Además, se pudo analizar el retroceso del acantilado en el lapso temporal 1977-2018. En la Zona Norte se pudo apreciar un 


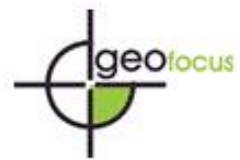

García González, P., Martínez G.A., Alvarez, M.F., Del Río, J.L., Taverna B.D, (2021). Evaluación de los procesos antrópicos y naturales que inducen la removilización de un campo de dunas sobre la ruta provincial 11, provincia de Buenos Aires, Argentina. GeoFocus (Artículos), Revista Internacional de Ciencia y Tecnología de la Información Geográfica, 27, 135-160. http://dx.doi.org/10.21138/GF.685

retroceso significativo, registrándose un valor promedio de $7,5 \mathrm{~m}$, siendo $14 \mathrm{~m}$ el valor máximo registrado y $1 \mathrm{~m}$ el mínimo. Como correlato en el mismo lapso se ha visto y medido un retroceso del acantilado que podría vincularse con una merma primaria en la depositación de arenas de playa, pero que deberá ser estudiada en detalle en otro trabajo.

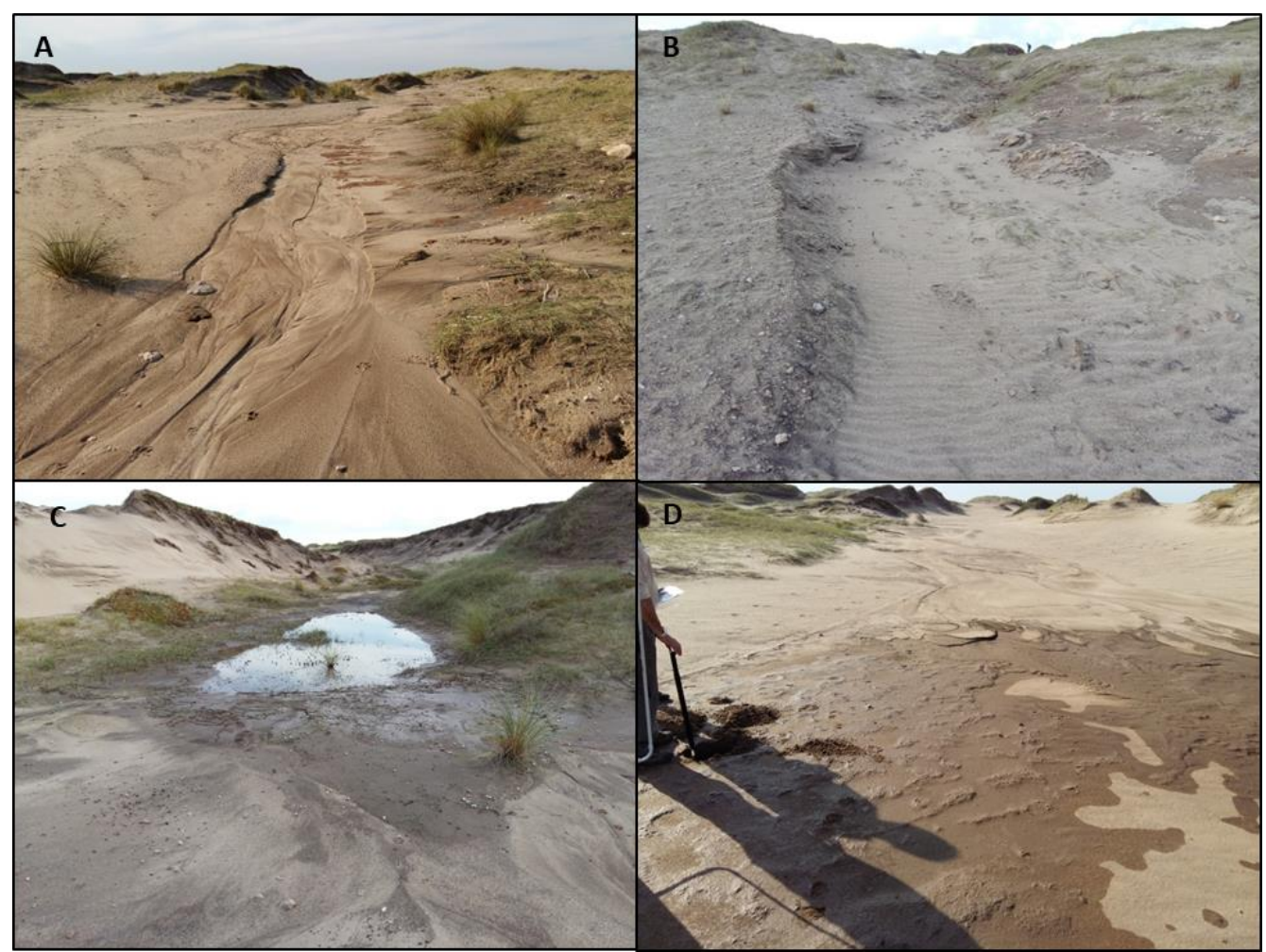

Figura 11. Imágenes representativas del estado del cuerpo medanoso. A: Rasgos de erosión de un curso efímero por la escorrentía del agua desde la cuenca deprimida hacia el arroyo, B: Rasgos de erosión eólica sobre el mismo curso anterior que en estas condiciones actúa como rampa eólica, $\mathrm{C}$ : Charca desarrollada sobre el Pampeano expuesto en un bajo intermédanos y D: Rasgos de un curso de agua efímero que aún está húmedo.

\section{Discusión}

A partir de la interpretación de las imágenes satelitales y las observaciones de campo se pudo determinar que el paisaje presente en la zona de estudio se corresponde con la descripción de los cuerpos medanosos realizada por Codignotto \& Aguirre (1993) para estos ambientes en la Barrera Medanosa Austral. En su evolución histórica, algunos de los médanos activos fueron fijados por vegetación de manera natural, estabilizándose y limitando el intercambio de sedimentos a la zona de la playa (Bértola 2006, Isla et al. 2001, Codignotto \& Kokot 2005).

La problemática ambiental que dio origen a esta investigación es la intrusión del frente de avance del médano activo sobre la Ruta 11. El origen de esta problemática se puede asociar con el impacto ambiental antrópico, favorecido además, por las condiciones atmosféricas de la zona. 
García González, P., Martínez G.A., Alvarez, M.F., Del Río, J.L., Taverna B.D, (2021). Evaluación de los procesos antrópicos y naturales que inducen la removilización de un campo de dunas sobre la ruta provincial 11, provincia de Buenos Aires, Argentina. GeoFocus (Artículos), Revista Internacional de Ciencia y Tecnología de la Información Geográfica, 27, 135-160. http://dx.doi.org/10.21138/GF.685

El impacto antrópico se ve reflejado en dos procesos. El primero de ellos es el aumento de la práctica del llamado deporte "doma de médanos" que consiste en el manejo de vehículos todoterreno (motos y cuadriciclos principalmente) por las rampas y desniveles que se generan en el paisaje dunar. Esta práctica altera la sucesión ecológica natural y modifica las geoformas haciendo que el paisaje se observe altamente fragmentado. El segundo proceso es la merma de la cantidad de sedimentos transportados por la deriva litoral debido a la construcción de barreras para evitar la erosión costera (Isla 2010). En la zona de estudio esta problemática se refleja en el retroceso del frente del acantilado y la disminución de la cantidad de arena en la playa que repercute directamente en el balance sedimentario playa/médano.

La tendencia encontrada en la Zona Sur se relaciona con un proceso efectivo de colonización vegetal (Vega de Seoane et al. 2007), la cual comienza desde la vegetación pionera que inicialmente era incipiente en los médanos semifijos. La presencia de este tipo de vegetación favorece el proceso de fijación de estos médanos, por medio de sus raíces, a la vez que participa en el entrampado de arenas y modifica la superficie en relación al flujo de viento (Packham \& Willis 1997). Este hecho, favorece la estabilización del sustrato. Esta sucesión primaria da lugar a una modificación en las propiedades físico-químicas del suelo (aumento de materia orgánica, aumento de retención humedad, acidificación, etc.), en particular en las zonas de interduna (S.3), favoreciendo el desarrollo de otras especies vegetales y dando lugar al desarrollo de una sucesión ecológica secundaria (Begon et al. 2006). Como consecuencia aumenta la diversidad y la cobertura vegetal, así los médanos semifijos pasan a estabilizarse y convertirse en médanos fijos (Fig. 4 A). No obstante, Tsoar (2005) sugirió que en general, es más probable que las dunas se estabilicen a que se reactiven, por lo cual se requieren perturbaciones de alta intensidad para reactivar dunas estabilizadas.

En la Zona Centro el equilibrio sedimentario es muy dinámico, a causa de su contacto con la playa, lo que hace a esta zona más variable y susceptible a los cambios dados por la influencia antrópica. Desde 1977 hasta 2011 se incrementó el impacto antrópico debido al tránsito de vehículos lo que dio lugar a la disminución de la superficie cubierta por médanos fijos y aumento de la superficie cubierta por médanos semifijos. El alto tránsito de vehículos todo terreno evidenciado en esta Zona pone de manifiesto que el impacto antrópico, reduce la cubierta vegetal y favorece la removilización de los sedimentos (Pérez García 2000). Desde 2011 a 2018 el impacto parece estabilizarse lo que permite un cambio en la tendencia evolutiva volviendo a aumentar la superficie cubierta por médanos fijos, lo que se relaciona con un proceso de recolonización vegetal de los médanos semifijos (Fig. 4 B). Esto se evidencia en el porcentaje de cobertura observado para esta zona (100\%).

En la Zona Norte, a pesar de las condiciones desfavorables exhibidas por la dinámica sedimentaria y el impacto antrópico, la sucesión vegetal vuelve a comenzar en aquellos lugares en los que se pueden asentar especies fijadoras primarias como Sporobolus coarctatus y Panicum sp. Este impacto genera un cambio drástico en el paisaje ya que el médano vivo que se ubicaba cercano a la playa, junto a la zona de rampas eólicas, avanza hacia la zona continental del cuerpo medanoso en dirección a la ruta (noreste) (Fig. 8). Este avance se ve favorecido por el trazado de caminos que eliminan la cobertura vegetal del médano fijo y descubre los sedimentos quedando estos disponibles para su transporte. La tasa de avance tiende a aumentar en los últimos años y su orientación es predominantemente noreste, por lo cual el frente del médano vivo llega al borde de la ruta, cubriéndola en algunas ocasiones. En las imágenes satelitales esta intrusión sobre la Ruta Provincial 11 es registrada por primera vez en 2014, lo que coincide con los registros de la DNV (Ing. Bolggieri, com. pers.). La orientación noreste de 
García González, P., Martínez G.A., Alvarez, M.F., Del Río, J.L., Taverna B.D, (2021). Evaluación de los procesos antrópicos y naturales que inducen la removilización de un campo de dunas sobre la ruta provincial 11, provincia de Buenos Aires, Argentina. GeoFocus (Artículos), Revista Internacional de Ciencia y Tecnología de la Información Geográfica, 27, 135-160. http://dx.doi.org/10.21138/GF.685

las citadas rampas eólicas coincide con la dirección de avance del frente del médano vivo lo que pone de relieve una conexión entre ambos procesos.

Por las condiciones geológicas de la zona de estudio el límite de erosión es el sustrato Pampeano, así el avance del frente del médano activo genera tras de sí una cuenca de deflación que corta el cuerpo medanoso al medio (Fig. 8 y 9 B). En esta cuenca se alternan médanos semifijos y activos con zonas de sustrato Pampeano expuesto, sobre el que se dispone y mueve el cuerpo medanoso. Su textura limo-arcillososa y diagénesis determina una baja permeabilidad relativa y resistencia a la acción erosiva. Estas sedimentitas plio-pleistocenas actúan como límite a la erosión quedando expuesto una vez que los sedimentos arenosos eólicos son removidos. Este sustrato se activa y funciona como corredor eólico o como superficie de drenaje del agua de lluvia (Fig. 11 A, B y C).

Los procesos sedimentarios en el área son muy dinámicos, los agentes erosivos agua y viento participan activamente en estos procesos. El primero moviliza los sedimentos en dirección de la pendiente hacia la playa por escorrentía superficial (cursos efímeros), mientras que el segundo los transporta hacia el interior del cuerpo medanoso por tracción y saltación (rampas eólicas) (Fig. 11). El desarrollo de la vegetación se ve condicionado por la removilización del sustrato y el enterramiento. Así la sucesión ecológica se ve truncada y solo se pueden observar procesos de sucesión primaria en los médanos semifijos donde se desarrollan especies pioneras. El desarrollo de un la cubierta vegetal superficial facilita el crecimiento de especies producto de la sucesión vegetal, haciendo que el porcentaje de cobertura sea una variable útil para predecir el valor potencial de los programas de plantación (Nordstrom et al. 2009).

En toda propuesta de estabilización de dunas el tiempo y la estabilidad son importantes para asegurar la sucesión de la vegetación, pero los esfuerzos humanos pueden acelerar la colonización modificando la forma de la duna o plantando especies específicas (Hotta et al. 1987, Mendelssohn et al. 1991, Miller et al. 2001, Nordstrom et al. 2009).

En función del análisis realizado, la propuesta de mitigación consiste en fijar con vegetación el frente del médano vivo para frenar el transporte eólico sobre la ruta. Para ello, se propone modificar la morfología del frente del médano, aportándole una estructura similar a una duna tipo, mediante el uso de maquinarias y equipos de movimientos de arena (palas y retroexcavadoras) (Fig. 12).

Una vez realizado el proceso de movimiento de sedimentos se debe proceder a la cobertura con vegetación. Se recomienda el uso de biomantas y la implantación de vegetación de rápido desarrollo y capacidad de colonización en las zonas más cercanas a la cinta asfáltica. En la parte interior del cuerpo medanoso se pueden instalar enquinchados que frenen el transporte eólico y permitan la depositación de arenas y así, favorecer la sucesión ecológica y la colonización primaria de algunas especies vegetales (Sporobolus coarctatus y Panicum sp). Existen diferentes materiales y diseños para la elaboración los enquinchados (Nordstrom \& Arens 1998, Nordstrom 2000, Miller et al. 2001). Finalmente, para que la vegetación se pueda instalar con éxito y se consiga la fijación del frente del médano, todo este sector intervenido ha de ser debidamente señalizado y protegido del tránsito humano.

Actualmente la zona de estudio es considerada como una reserva natural incluida en la ordenanza municipal $\mathrm{N}^{\circ} 19111$ desde el año 2009. Dicha ordenanza menciona que la reserva se encuentra en una "situación de abandono, falta de interés, de control y de normas". Teniendo 


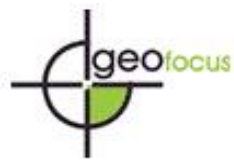

García González, P., Martínez G.A., Alvarez, M.F., Del Río, J.L., Taverna B.D, (2021). Evaluación de los procesos antrópicos y naturales que inducen la removilización de un campo de dunas sobre la ruta provincial 11, provincia de Buenos Aires, Argentina. GeoFocus (Artículos), Revista Internacional de Ciencia y Tecnología de la Información Geográfica, 27, 135-160. http://dx.doi.org/10.21138/GF.685

en cuenta esto y el impacto antrópico observado en dicha zona, proponemos la siguiente zonificación que divide el área en distintas zonas de manejo (Fig. 13):

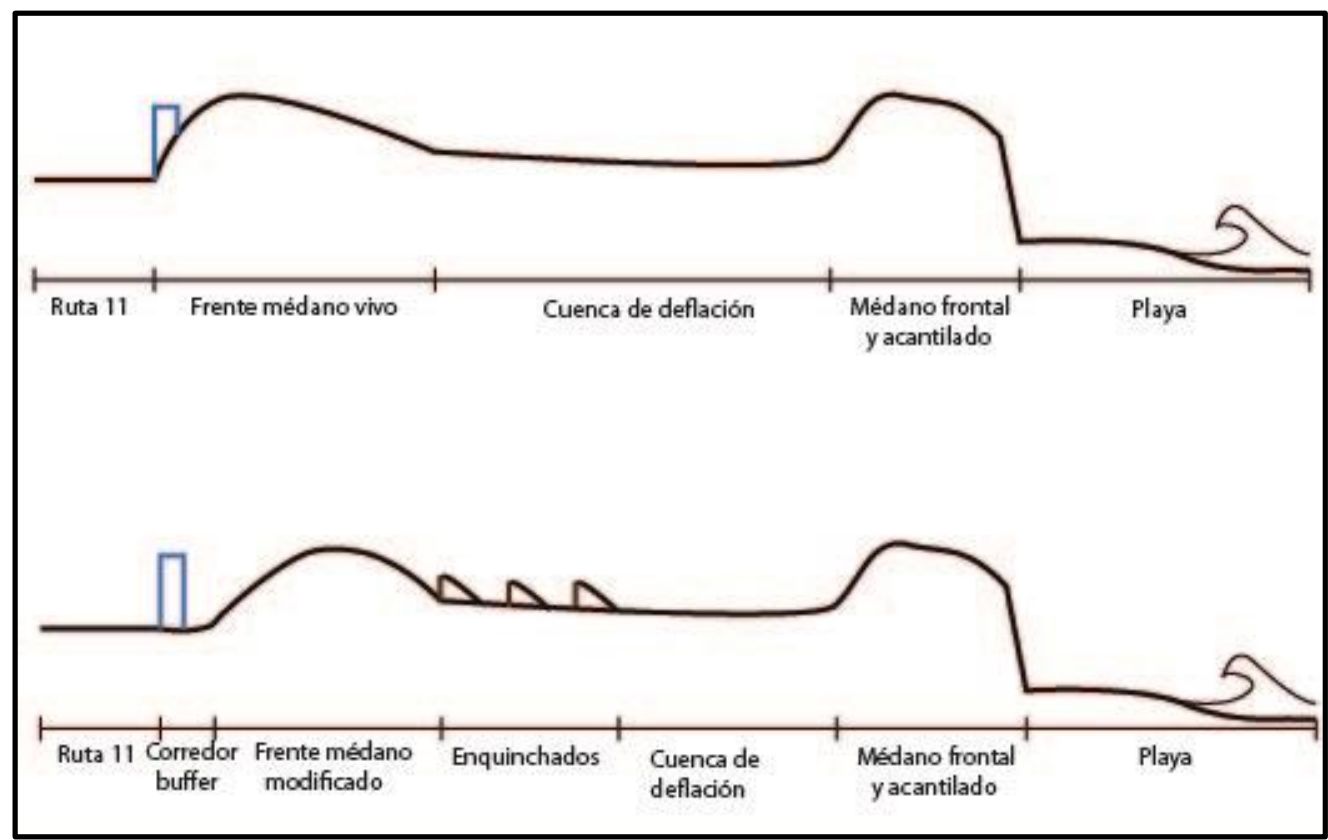

Figura 12. Esquema del perfil del frente del médano vivo y el cuerpo medanoso. A: Estado actual y B: Propuesta de modificación estructural. En azul se representa la parada de colectivos sobre la ruta de manera referencial.

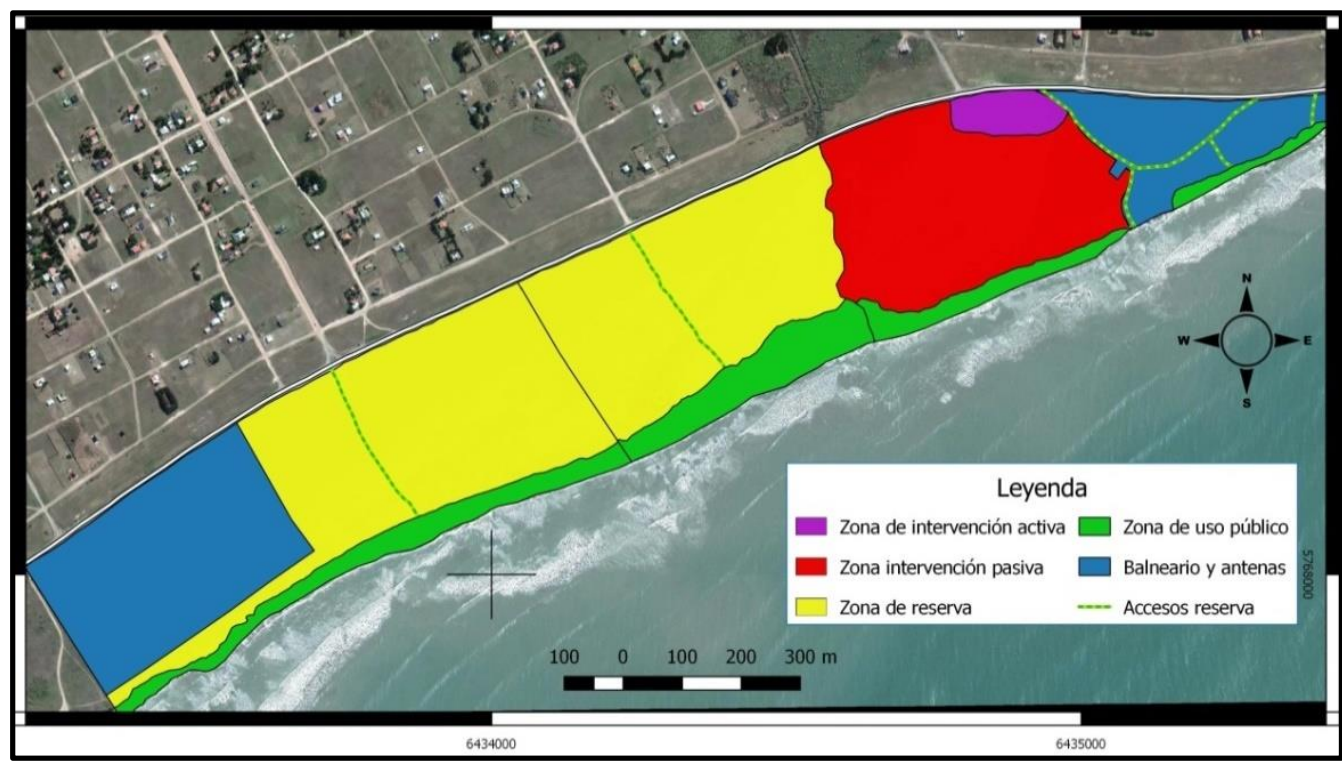

Figura 13: Plano de la propuesta de zonificación del área de la reserva. 
García González, P., Martínez G.A., Alvarez, M.F., Del Río, J.L., Taverna B.D, (2021). Evaluación de los procesos antrópicos y naturales que inducen la removilización de un campo de dunas sobre la ruta provincial 11, provincia de Buenos Aires, Argentina. GeoFocus (Artículos), Revista Internacional de Ciencia y Tecnología de la Información Geográfica, 27, 135-160. http://dx.doi.org/10.21138/GF.685

- Zona de intervención activa: se corresponde al frente del médano vivo de la Zona Norte (Fig. 13). En este sector las actividades previstas deben incluir el desarrollo de enquinchados que permitan un proceso de sedimentación natural de las arenas en tránsito. El objetivo de las acciones que se desarrollen en esta zona es reducir el impacto antrópico y permitir el desarrollo de los procesos naturales que permiten la estabilidad y fijación de los médanos. Su acceso se restringe mediante un cercado y solo se permitirá el acceso para el monitoreo y mantenimiento.

- Zona de intervención pasiva: se corresponde con toda la extensión de la Zona Norte, incluyendo los sistemas de captación pasivos. El objetivo de esta zona es permitir al sistema que se regenere de manera natural y evolucione hacia un paisaje natural que ayudará a mitigar la problemática ambiental. Se debe restringir el tránsito vehicular permitiendo solo aquellas actividades que garanticen la conservación del sistema, quedando excluidas aquellas actividades como el uso de fuego, acampada, tránsito de VTT, extracción de arena, tala, etc.

- Zona de reserva: corresponde al cuerpo medanoso en la Zona Sur y Centro. Abarca tanto los médanos fijos como los semifijos y activos. Su objetivo es el de conservar las geoformas y la vegetación, permitiendo a su vez el desarrollo de la sucesión ecológica vegetal. De esta este modo se permite al sistema que se regenere de manera natural y evolucione hacia un paisaje natural, reduciéndose al máximo las actividades que pudieran generar cambios a la estabilidad del mismo. El acceso a esta área debe ser controlado y exclusivamente a pie; se contemplan sólo actividades de investigación científica, educación ambiental y de esparcimiento.

- Zona de uso público: se restringe al área de la playa para permitir el uso público de este recurso. Su objetivo es ofrecer espacios equipados para las actividades vinculadas al turismo, la recreación y la educación ambiental e interpretación de la naturaleza. Los accesos deben estar bien señalizados y restringidos a ciertos sectores para permitir el acceso a la playa. Se debe contar con cartelería de información sobre actividades permitidas, valor ecosistémico y paisajístico del área.

Esta propuesta de gestión precisa de un mantenimiento y monitoreo a lo largo del tiempo que permita conservar y optimizar el proceso de fijación del frente del médano vivo. Una vez establecida la vegetación se debe mantener un control sobre todo después de eventos de tormentas, vientos fuertes y sudestadas (Lasta et al. 2010). Además, a largo plazo se debe mantener la atención en la segunda parte de la gestión referente a la conservación de la reserva.

\section{Conclusiones}

El presente trabajo permitió obtener una caracterización integral de la zona de estudio, la cual se pretende que sirva como base para futuras consideraciones con respecto al manejo del ambiente y la mitigación de las consecuencias de un uso inadecuado del ambiente costero.

La evolución del paisaje en el área de estudio está condicionada por cuatro factores: la dinámica sedimentaria (erosión/depositación), la cobertura vegetal, el grado de sucesión ecológica y el impacto antrópico, determinado por el uso de los médanos para tránsito de motos y VTT. 


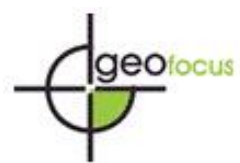

García González, P., Martínez G.A., Alvarez, M.F., Del Río, J.L., Taverna B.D, (2021). Evaluación de los procesos antrópicos y naturales que inducen la removilización de un campo de dunas sobre la ruta provincial 11, provincia de Buenos Aires, Argentina. GeoFocus (Artículos), Revista Internacional de Ciencia y Tecnología de la Información Geográfica, 27, 135-160. http://dx.doi.org/10.21138/GF.685

En la Zona Sur la evolución temporal de los médanos tiene una tendencia al aumento de la superficie cubierta por médanos fijos, reduciéndose, por ende, la superficie de médanos semifijos y activos.

En la Zona Centro, la evolución está estrechamente vinculada al impacto ambiental por el tránsito de VTT. Desde 1977 hasta 2011 se incrementó la superficie cubierta por médanos semifijos, concomitantemente con el aumento de sendas. Desde 2011 a 2018 el estado parece estabilizarse, volviendo a aumentar la superficie cubierta por médanos fijos, vinculado con un proceso de recolonización vegetal de los médanos semifijos.

En la Zona Norte, la más activa de las tres, la tendencia es a la reducción de la superficie cubierta por médanos fijos desde 1977 a 2011, por el aumento y persistencia del tránsito de VTT. Ello ocasionó el avance del frente del médano vivo en dirección noreste, cubriendo la traza de la Ruta 11. A medida que se produjo este transporte, la cobertura de arena disminuyó por un efecto combinado con un transporte ácueo en dirección opuesta al avance del médano, dejando aflorante el sustrato limo-arenoso que conforma una rampa o cubeta de deflación. Por otro lado, la intrusión del médano sobre la traza de la ruta, estaría relacionada a tormentas intensas del SE que reactivan el transporte eólico en dicha rampa.

Las comunidades vegetales presentes en el cuerpo medanoso concuerdan con las especies ya descriptas para este ambiente. Predominan las especies nativas sobre las exóticas, siendo Carpobrotus edulis, Panicum sp. y Sporobolus coarctatus las principales especies fijadoras.

El retroceso del borde del acantilado se estimó en 7,5 m, en algunos sectores del área de estudio, para el lapso temporal desde 1977-2018.

La propuesta de gestión para la zona de estudio, involucra acciones directas sobre el cuerpo medanoso, monitoreo de las intervenciones realizadas, zonificación del área y tareas de educación y concientización de la sociedad. Esta propuesta se hizo llegar las autoridades de Dirección Provincial de Vialidad, con el fin de proteger el ambiente de dunas y dar una solución sustentable a este problema ambiental.

\section{Agradecimientos}

Los autores de este trabajo queremos expresar nuestro agradecimiento al Instituto de Geología de Costas y a la UNMdP por permitir el desarrollo de la investigación, así como al apoyo e información brindada por la Dirección Provincial de Vialidad de la Zona X. Finalmente queremos agradecer a los compañeros que aportaron su ayuda desinteresada en las diferentes partes de la investigación.

\section{Referencias bibliográficas}

Andersen, U.V. (1995). "Resistance of Danish coastal vegetation types to human trampling". Biological Conservation, 71, 223-230.

Arnot, R.D. (2010). An introduction to coastal processes and geomorphology. UK, Ed. Cambridge University Press. 


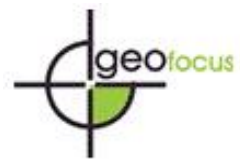

García González, P., Martínez G.A., Alvarez, M.F., Del Río, J.L., Taverna B.D, (2021). Evaluación de los procesos antrópicos y naturales que inducen la removilización de un campo de dunas sobre la ruta provincial 11, provincia de Buenos Aires, Argentina. GeoFocus (Artículos), Revista Internacional de Ciencia y Tecnología de la Información Geográfica, 27, 135-160. http://dx.doi.org/10.21138/GF.685

Azuz, I. A. (2004). "El manejo de los cambios en la morfología costera". El manejo costero en México. Universidad Autónoma de Campeche. Capitulo: 16. 235-252.

Begon, M. Harper, J.L. \& Townsend, C.R. (1990). Ecology. Boston, MA, Blackwell Scientific Publications.

Bértola, G.R. (2006). "Morfodinámica de playas del sudeste de la Provincia de Buenos Aires (1983 a 2004)". Latin American Journal of Sedimentology and Basin Analysis, 13, 1, 31-57.

Bértola, G.R. \& Merlotto, A. (2010). "Los médanos de Lobería y Necochea". Manual de manejo de barreras medanosas de la provincia de Buenos Aires. Ed.129-160.

Blott, S. \& Pye, K. (2001). "GRADISTAT: a grain size distribution and statistics package for the analysis of unconsolidated sediments". Earth Surface Processes and Landforms 26, 12371248.

Bonaparte, J. (1960). "La sucesión estratigráfica de Monte Hermoso (Prov. Buenos Aires)". Acta Geológica Lilloana III, 273-290.

Braun-Blanquet, J. (1932). Plant sociology: the study of plant communities. McGraw-Hill Publications in the Botanical Sciences. New York.

Brown, A.C. \& McLachlan, A. (2002). Sandy shore ecosystems and the threats facing them: some predictions for the year 2025. Published online by Cambridge University Press.

Brownett, J.M. \& Mills, R.S. (2017). "The development and application of remote sensing to monitor sand dune habitats". Journal of Coast Conservation, 21, 643-656.

Cabrera, A.L. (1941). Las comunidades vegetales de las dunas costaneras de la provincia de Buenos Aires. La Plata (Argentina), DAGI, 1, 2, 1-44.

Camino, M.A., López de Armentia, A., Oyarbide, R.F. y del Río, J.L. (2001). "Análisis de la variación de la calidad ambiental mediante la utilización de índices cuantitativos en el litoral atlántico del sudeste de la provincia de Buenos Aires, Argentina. El caso de Mar del Sur". Actas de la III Reunión de Geología Ambiental y Ordenación del Territorio del Área del Mercosur y I Simposio de Geoindicadores Ambientales, 32.

Camino, M. y Padilla, L. (2008). "Evaluación geoambiental preliminar de riesgo costero y diagnóstico ambiental del riesgo en Mar del Sud, partido de General Alvarado, provincia de Buenos Aires”. Revista Párrafos Geográficos, 7, 1, 34-59.

Codignotto, J.O. \& Aguirre, M.L. (1993). "Coastal evolution, changes in sea level and molluscan fauna in northeastern Argentina during the Late Quaternary". Marine Geology, 1, 110, 163-175.

Codignotto, J.O. \& Kokot, R.R. (2005). "Geomorfología del sector litoral de la provincia de Buenos Aires". XVI Congreso Geológico Argentino.

Dadon, J.R., Chiappini, G. y Rodríguez, M.C. (2002). "Impactos ambientales del turismo costero en la Provincia de Buenos Aires". Gerencia Ambiental, 9, 88, 552-560.

del Río, J.L., Patat, L., Lucero, M., Zamora, A., Moschione, E., Bó, M.J., Camino, M., López de Armentia, A. y Farenga, M. (2016). "Ensayo de un sistema de indicadores sincrónico y diacrónico para la determinación de calidad ambiental en playas turísticas de la costa atlántica bonaerense". Revista de Geología Aplicada a la Ingeniería y al Ambiente, 37, 13-28. 


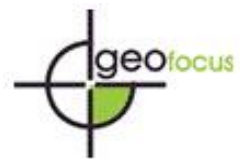

García González, P., Martínez G.A., Alvarez, M.F., Del Río, J.L., Taverna B.D, (2021). Evaluación de los procesos antrópicos y naturales que inducen la removilización de un campo de dunas sobre la ruta provincial 11, provincia de Buenos Aires, Argentina. GeoFocus (Artículos), Revista Internacional de Ciencia y Tecnología de la Información Geográfica, 27, 135-160. http://dx.doi.org/10.21138/GF.685

del Río, J.L., Piantanida, F., Antenucci, D., Molina, H.D., Cicchino, A., Denisienia, N., Martínez, G.A., Taverna, B.D., Farenga, M., y Lupo, S. (2017). "Huella geomorfológica de actividades mineras en las dunas de la barrera oriental de la costa atlántica bonaerense: relación con otras actividades". III Congreso Argentino de Áridos.

Fadhil, A.M. (2013). "Sand dunes monitoring using remote sensing and GIS techniques for some sites in Iraq". PIAGENG 2013: Intelligent Information, Control, and Communication Technology for Agricultural Engineering, edited by Honghua Tan, Proc. of SPIE Vol. 8762, 876206.

Faggi, A.M., \& Dadon, J. (2010). "Vegetation changes associated to coastal tourist urbanizations". Multequina, 19, 53-75.

Folk, R.L. \& Ward, W.C. (1957). "Brazos river bar. A study in the significance of grain size parameters". Journal of Sedimentary Petrology, 27, 3-26.

Foster-Smith, J., Birchenough, A.C., Evans, S.M. \& Prince, J. (2007). "Human impacts on Cable Beach, Broome (Western Australia)". Coastal Management, 35, 181-194.

García, M.C. y Veneziano, M.F. (2005). "Estrategias de ordenación para un sector costero vulnerable: El Marquesado- San Eduardo del Mar”. Párrafos Geográficos, IV, 4.

Godfrey, P.J. \& Godfrey, M.M., (1981). "Ecological effects of off-road vehicles on Cape Cod". Oceanus 23, 56-67.

Grottoli, E., Biausque, M., Rogers, D., Jackson, D. \& Cooper, W. (2020). "Structure-fromMotion-Derived Digital Surface Models from Historical Aerial Photographs: A New 3D Application for Coastal Dune Monitoring”. Remote Sensing, 13-95.

Hesp, P., Schmutz, P., Martinez, M.L., Driskell, L., Oregera, R., Renken, K., Revelo, N.A.R. \& Orocio, O.A.J. (2010). "The effect on coastal vegetation of trampling on a parabolic dune". Aeolian Research 2, 105-111.

Hotta, S., Kraus, N.C. \& Horikawa, K. (1987). "Function of sand fences in controlling windblown sand". In: Coastal Sediments'87. American Society of Civil Engineers, New York, pp. 772-787.

Isla, F.I., Cortizo, L.C. y Turno Orellano, H.A. (2001). "Dinámica y evolución de las barreras medanosas. Provincia de Buenos Aires, Argentina". Revista Brasileira de Geomorfología, 2, 1, 73-83.

Isla, F.I. (2003). "Disponibilidad de arena para el refulado de las playas de Miramar y Chapadmalal, Argentina". Revista de la Asociación Geológica Argentina, 58, 3, 311-320.

Isla, F. I. (2010). "Introducción al manejo de barreras medanosas". Manual de manejo de barreras medanosas de la provincia de Buenos Aires. Ed. p.7-26.

Kidd, R. (2001). Coastal dune management: a manual of coastal dune management and rehabilitation techniques. NSW Government publication ISBN 0.7347. 5202.4.

Kraglievich, J. (1959). "Contribuciones al conocimiento de la geología cuaternaria en la Argentina. IV- Nota acerca de la geología costera en la desembocadura del Arroyo Malacara (Prov. Buenos Aires)". Comunicaciones del Museo Argentino de Ciencias Naturales B. Rivadavia, Geología, I, 17, 3-9. 


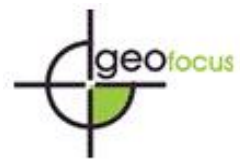

García González, P., Martínez G.A., Alvarez, M.F., Del Río, J.L., Taverna B.D, (2021). Evaluación de los procesos antrópicos y naturales que inducen la removilización de un campo de dunas sobre la ruta provincial 11, provincia de Buenos Aires, Argentina. GeoFocus (Artículos), Revista Internacional de Ciencia y Tecnología de la Información Geográfica, 27, 135-160. http://dx.doi.org/10.21138/GF.685

Lasta, C., Ezpeleta, L., González, E. \& Roselli, D. (2010). "Estrategia de fijación de dunas costeras: evaluación metodológica y económica en el Partido de La Costa". Manual de manejo de barreras medanosas de la provincia de Buenos Aires. Ed. p.39-48.

Levin, N., Elie Jablon. P., Phinn, S. \& Collins, K. (2017). "Coastal dune activity and foredune formation on Moreton Island, Australia, 1944-2015”. Aeolian Research, 25, 107-121.

Lithgow, D., Martínez, M., Gallego-Fernández, J., Hesp, P., Flores, P., Gachuz, S., RodríguezRevelo, N., Jiménez-Orocio, O., Mendoza-González, G. \& Álvarez-Molina, L. (2013); "Linking restoration ecology with coastal dune restoration". Geomorphology, 199, 214-224.

Marcomini, S.C. \& López, R.A. (2005). "Morfodinamica costera entre Punta Florida y Costa Bonita, Provincia de Buenos Aires". XVI Congreso Geológico Argentino, 3: 553-558.

Marcomini, S.C. \& López, R.A. (2006). "Geomorfología costera y explotación de arena de playa en la Provincia de Buenos Aires y sus consecuencias ambientales". Revista Brasileira e geomorfología. Año 7, nº 2.

Marcomini, S.C. \& López, R. (2008). "Morfodinamica de rampas eólicas en la costa sur de la provincia de Buenos Aires". XII Reunión Argentina de Sedimentología, Buenos Aires, Argentina.

Marcomini, S., López, R., Picca, P., Madanes, N. y Bertolin, L. (2011). "Cambios en la vegetación en costas de dunas y su influencia en el balance sedimentario. Problemática de los Ambientes Costeros, Sur de Brasil, Uruguay y Argentina". Croquis, Buenos Aires, 193-205.

Mather, A.S. \& Ritchie, W. (1977). The Beaches of the Highlands and Islands of Scotland. Countryside Commission for Scotland, Perth.

Matteucci, S.D. y Colma, A. (1982). Metodología para el estudio de la vegetación. Secretaría General de la Organización de los Estados Americanos. Programa Regional de Desarrollo Científico y Tecnológico. Washington DC. 160pp.

Mendelssohn, I.A., Hester, M.W., Monteferrante, F.J. \& Talbot, F. (1999). "Experimental dune building and vegetative stabilization in a sand-deficient barrier island setting on the Louisiana coast, USA". Journal of Coastal Research, 7, 137-149.

Miller, D.L., Thetford, M. \& Yager, L. (2001). "Evaluating sand fence and vegetation for dune building following overwash by Hurricane Opal on Santa Rosa Island, Florida". Journal of Coastal Research, 17, 936-948.

Morello, J.H., Buzai, G.D., Baxendale, C., Rodríguez, A., Matteucci, S., Godagnone, R. \& Casas, R. (2000). "Urbanización y consumo de tierra fértil". Ciencia Hoy, 10, 50-61.

Nordstrom, K.F. \& Arens, S.M. (1998). "The role of human actions in evolution and management of foredunes in The Netherlands and New Jersey, USA". Journal of Coastal Conservation 4, 169-180.

Nordstrom, K.F. (2000). Beaches and Dunes of Developed Coasts. Cambridge University Press, Cambridge.

Nordstrom, K.F. (2008). Beach and dune restoration. Cambridge University Press, Cambridge. 
García González, P., Martínez G.A., Alvarez, M.F., Del Río, J.L., Taverna B.D, (2021). Evaluación de los procesos antrópicos y naturales que inducen la removilización de un campo de dunas sobre la ruta provincial 11, provincia de Buenos Aires, Argentina. GeoFocus (Artículos), Revista Internacional de Ciencia y Tecnología de la Información Geográfica, 27, 135-160. http://dx.doi.org/10.21138/GF.685

Nordstrom, K.F., Gamper, U., Fontolan, G., Bezzi, A. \&. Jackson, N.L. (2009). "Characteristics of Coastal Dune Topography and Vegetation in Environments Recently Modified Using Beach Fill and Vegetation Plantings, Veneto, Italy". Environmental Management, 44, 1121-1135.

Ordenanza municipal No 10011 (1995). Boletín Municipal: 1459, p.3-4 (18/08/1995). Mar del Plata, Argentina.

Ordenanza municipal $N^{\circ} 19111$ (2009). Boletín Municipal: 2068, p. 5 (10/06/2009). Mar del Plata, Argentina.

Packham, J.R. \& Willis, A.J. (1997). Ecology of dunes, salt marsh and shingle. Londres, Chapman \& Hall, 235 pp.

Pérez García, R.E. (2000). "Impacto ambiental en playas y dunas por el uso de vehículos todo terreno". https://playasbonaerenses.files.wordpress.com/2011/04/vtt1.pdf

Tsoar, H. (2005). "Sand dunes mobility and stability in relation to climate". Physica A, 357, 1, 50-56.

Vega de Seoane, C.L., Fernandez, J.B.G. \& Pascual, C.V. (2007). Manual de restauración de dunas costeras. Dirección General de Costas. Ministerio de Medio Ambiente. Gobierno de España.

Walkley, A. \& Black, A. (1965). "Organic carbon" in Method of Soil Analysis, Part 2: Chemical and Microbiological Properties, Ed. by C. Black (American Society of Agronomy, Madison, WI, 1965), 1372-1375.

Wentworth, C.K. (1929). "Method of computing mechanical composition types in sediments". Geol. Soc. Amer. Bull., 40, 771-790.

Witkin, G., Vorano, C., Bellagamba, P. \& Giampietri, L. (2003). Plan de Manejo de Reserva Turística y Forestal Paseo Costanera Sur, Municipio Gral. Pueyrredon, Buenos Aires, DGA. Municipalidad de Gral. Pueyrredon, Mar del Plata.

Zárate, M. \& Fasano, J. (1989). "The Plio-Pleistocene record of the central eastern Pamapas, Buenos Aires Province, Argentina: The Chapadmalal case study". Palaeogeography, Palaeoclimatology, Palaeoecology, 72: 27-52.

Zavala, C. (1993). "Estratigrafía de la localidad de Farola Monte Hermoso (pliocenoReciente)". XII Congreso Geológico Argentino y II Congreso de Explotación de Hidrocarburos, Actas 2: 228-235. 